\title{
Contract Renegotiation, Mechanism Design, and the Liquidated Damages Rule
}

\author{
Eric L. Talley*
}

The common law practice of refusing to enforce contractual penalties has long mystified law and economics scholars. After critiquing the prevailing law and economics analyses of the common law rule, Eric L. Talley reevaluates the penalty doctrine using the game theoretic technique of mechanism design, which facilitates the analysis of multiparty bargaining situations under various assumptions. Using this technique to model the allocational consequences of various enforcement regimes that courts might adopt with respect to stipulated damages clauses, Mr. Talley finds that penalty nonenforcement can increase economic efficiency by discouraging strategic behavior by the parties, thereby inducing more efficient contract renegotiation.

\section{INTRODUCTION}

Within neoclassical economics, freedom of contract holds a singular status, nearly equivalent to that of a natural right. Indeed, an oft-recited theme in the law and economics literature is that when individuals act rationally, and transaction costs are negligible, restrictions on contractual freedom cannot enhance economic efficiency. 1

Nevertheless, common law courts frequently have eschewed this classical view of economic liberty, opting instead to constrain contractual freedom in the interest of public policy. ${ }^{2}$ A noteworthy and long-standing example of courts'

* J.D./Ph.D. Candidate, Stanford Law School and Economics Department. The author gratefully acknowledges the John M. Olin Program in Law and Economics and the Stanford Center on Conflict and Negotiation for their generous financial support. Many thanks to Richard Craswell, Barbara Fried, Giovanni Maggi, Peter Menell, A. Mitchell Polinsky, Margaret Jane Radin, Bob Wilson, and seminar participants at Stanford Law School and Economics Department for their helpful comments. Special thanks to Ian Ayres, who provided invaluable advice and encouragement. All errors are, of course, mine.

1. See, e.g., R.H. Coase, The Problem of Social Cost, 3 J.L. \& Econ. 1 (1960); AnthonY T. Kronman \& Richard Posner, The Economics of Contract Law 2-3 (1979).

The term "rational" as used here signifies that individuals act so as to maximize their own predetermined criteria for happiness, or "utility." In its strictest form, rationality implies that each individual accurately discerns the consequences of her actions and others' probable reactions. Note that this definition of rationality is means-related, since it assumes that the "goals" of each individual are fixed a priori and hypothesizes how the individual acts to achieve those ends. For a discussion extending the concept of rationality beyond means-based analysis, see Richard H. Fallon, Jr., Two Senses of Autonomy, 46 Stan. L. Rev. 875 (1994). The term "transaction costs" is a catch-all phrase that includes bargaining and other contracting costs, agency costs, uncertainty, and information costs.

2. From a constitutional standpoint, the notion of contractual liberty has a spotted history. During the so-called "Lochner era," from 1905 to 1934, the United States Supreme Court, citing freedom of contract as a fundamental right, struck down some 200 state regulations that constrained contractual 
resistance is the common law policy toward "stipulated damage" provisions. ${ }^{3}$ A stipulated damage clause is a contractual covenant prescribing an explicit payment from one contracting party (or parties) to another contracting party (or parties) should the former breach the contract. ${ }^{4}$ Common law courts routinely decline to enforce these contractual provisions if the stipulated sum is "unreasonable" or "excessive" relative to the damages of the aggrieved party, thereby constituting a "penalty." A stipulated damage clause is enforceable as a valid "liquidated damages" term only if it can survive a judicial reasonability test. ${ }^{5}$

The penalty doctrine constrains contractual freedom by definition. Not surprisingly, then, numerous law and economics scholars maintain that the doctrine is little more than an anachronistic artifact of judicial paternalism. ${ }^{6}$ These scholars tend to argue that penalty nonenforcement is both inconvenient and grossly inefficient, since stipulating damages may be the only way parties can signal the quality of their goods, screen their trading partners, or provide efficient insurance for "idiosyncratic" tastes.

This discrepancy between traditional economic theory ${ }^{7}$ and historical legal practice has made meaningful analysis of the penalty doctrine somewhat confusing. Adding to this quagmire, the much-dreaded Coase theorem suggests that the doctrine may have few (if any) efficiency implications. For the Coase

freedoms. By 1938, however, the Court recanted this view, holding that the law should remain neutral to any economic theory, a posture the Court arguably maintains today. See Gerald GuntHer, ConstITUTIONAL Law 439-65 (12th ed. 1991).

3. These provisions are commonly known as "liquidated damage" terms. This label, however, correctly describes only those stipulated terms that are legally enforceable. Therefore, the term "stipulated damages," as used in this note, refers to any damages term stipulated in a contract, regardless of its enforceability.

4. For example, consider the following contract: "A promises to deliver 20 widgets to B's residence on or before January 1,1999, and, upon delivery, B covenants to pay A consideration of $\$ 150$ per widget. Should $A$ fail to deliver all of the widgets on or before the above date, A shall pay $B \$ 10$ per diem for late delivery." The second sentence of this hypothetical contract is a type of stipulated damage clause.

5. For a more precise legal and economic description of these terms, see text accompanying notes 24-46 infra.

6. E.g., Robert Cooter \& Thomas Ulen, Law ANd Economics 293 (1988) ("There are now sound theoretical reasons for believing that liquidated damages-and other forms of stipulated remedy-should be routinely enforced by the court, even if they appear to contain a punitive element."); KRONMAN \& POSNER, supra note 1, at 261 ("Of the three paternalistic limitations we have considered in this note, the prohibition on penal clauses is both the most important, from a practical point of view, and the least defensible from an economic point of view-or any other."); RICHARD A. POSNER, ECONOMIC ANALYSIS OF LAW 233 (3d ed. 1986) (citing the penalty doctrine as one of "[t]he most important counterexamples ... . [of] the efficiency theory of the common law"); Charles J. Goetz \& Robert E. Scott, Liquidated Damages, Penalties and the Just Compensation Principle: Some Notes on an Enforcement Model and a Theory of Efficient Breach, 77 CoLum. L. REv. 554, 594 (1977) ("In sum, contemporary cost-benefit analysis suggests that the traditional penalty rule is anachronistic . . . ."); Alan Schwartz, The Myth that Promisees Prefer Supracompensatory Remedies: An Analysis of Contracting for Damage Measures, 100 YALE L.J. 369, 370 (1990) (arguing that both the "ex ante" and the "ex post" versions of the doctrine are theoretically unsound). Judge Posner has been highly critical of the doctrine as well in his Seventh Circuit opinions. See, e.g., Lake River Corp. v. Carborundum Co., 769 F.2d 1284, 1288-89 (7th Cir. 1985) (holding a stipulated damages clause invalid under Illinois common law, yet criticizing the common law refusal to enforce penalty clauses as "paternalistic" and "odd").

7. By "traditional economic theory" I mean the so-called classical and neoclassical schools of economic thought. These are differentiated from the less frictionless models of transaction cost economics and information economics. 
theorem asserts that so long as transaction costs are sufficiently small, courts' enforcement policies are irrelevant. The parties will always have the incentive and ability to implement a socially efficient allocation ${ }^{8}$ through bilateral bargaining, regardless of whether or not courts enforce stipulated terms. ${ }^{9}$

In the real world, however, transaction costs can undermine the predictions of the Coase theorem by hindering negotiation between parties. In such circumstances, legal rules that best mitigate the effects of transaction costs are often the most efficient. ${ }^{10}$ Thus, if there is any efficiency justification for the penalty doctrine, it likely comes from a transaction cost rationale.

A number of recent efforts in the law and economics literature attempt to provide transaction cost justifications for the penalty doctrine. These theories posit that nonenforcement of penalty clauses may be a way to overcome the problems of opportunism, externalities, or signaling costs, all of which create inefficiencies if left unchecked. ${ }^{11}$ Nearly all of these rationales, however, suf-

8. For the purposes of this note, a "socially efficient" allocation is one that maximizes the sum of individuals' welfare. This efficiency criterion is often denoted as the "Kaldor-Hicks" measure, and it ranks allocations assuming that the "winners" under a specific allocation potentially can compensate the "losers," thereby making society better off as a whole. See POSNER, supra note 6, at 11 . While the philosophical and theoretical objections to any social welfare function are well documented, see, e.g., 1 Kenneth J. Arrow, Collected Papers: Social Choice and Justice (1980); Jules Coleman, Efficiency, Utility, and Wealth Maximization, 8 Hofstra L. Rev. 487 (1980); Gregori Crespi, The Mid-Life Crisis of the Law and Economics Movement, 67 NOTRE DAME L. Rev. 231 (1991), this note reluctantly adopts the Kaldor-Hicks measure so that some type of welfare analysis is feasible. See Cooter \& ULEN, supra note 6, at 51 (noting that the Kaldor-Hicks metric is "indispensable" to applied welfare economics).

9. See Coase, supra note 1 , at 10 .

To illustrate this phenomenon, consider the situation where individuals $\mathrm{X}$ and $\mathrm{Y}$ stipulate damages of $\$ 100$ in case of breach by X, but Y's damages turn out to be only $\$ 10$, and $X$ can gain $\$ 50$ by breaching. If courts regularly enforced stipulated terms, and renegotiation is impossible, $\mathrm{X}$ would fail to breach even though it would be obviously efficient to do so. One might argue, then, that the rule against penalties eliminates the possibility that $\mathrm{X}$ will perform inefficiently. See, e.g., John Barton, The Economic Basis of Damages for Breach of Contract, 1 J. LEGAL Stud. 277, 291 (1972); Note, Liquidated Damages as Prima Facie Evidence, 51 IND. L.J. 189, 190 (1975).

While this explanation is popular, it falls prey to a Coase theorem critique when the parties can renegotiate the stipulated term. Any renegotiated damages amount between $\$ 10$ and $\$ 50$ would induce efficient breach, making both parties better off. The parties would thus have an incentive to implement a pareto efficient allocation through bilateral bargaining, regardless of the courts' enforcement policy. This simple Coasean logic suggests that, in the absence of substantial transaction costs, the penalty doctrine has no effect on allocational efficiency.

10. This statement is generally true, but there may be factors other than transaction costs that come into play. For instance, a particular legal rule might minimize transaction costs of negotiation, but simultaneously force the parties to bear greater amounts of risk ex ante. In this case, it is unclear whether the rule is "efficient" in an overall sense. Nevertheless, minimizing transaction costs is an important efficiency goal.

11. See Philippe Aghion \& Patrick Bolton, Contracts as a Barrier to Entry, 77 AM. Econ. Rev. 381, 389-92 (1987) (arguing that stipulated damage clauses can inefficiently create barriers to entry); Philippe Aghion \& Benjamin Hermalin, Legal Restrictions on Private Contracts Can Enhance Efficiency, 6 J.L. EcoN. \& ORG. 381, 381 (1990) (positing that costly "signalling" may provide a potential justification for the rule); Joseph F. Brodley \& Ching-to Albert Ma, Contract Penalties, Monopolizing Strategies, and Antitrust Policy, 45 STAN. L. Rev. 1161 (1993) (providing a framework in antitrust law for attacking contractual penalties that erect entry barriers); Tai-Yeong Chung, On the Social Optimality of Liquidated Damage Clauses: An Economic Analysis, 8 J.L. Econ. \& ORG. 280, 283 (1992) (arguing that the implementation of large contractual penalties creates inefficient rent seeking); Kenneth W. Clarkson, Roger LeRoy Miller \& Timothy J. Muris, Liquidated Damages v. Penalties: Sense or Nonsense?, 1978 WIs. L. REv. 351, 368 (noting penalties may give promisees the incentive to induce ineffi- 
fer from a combination of two shortcomings. First, they tend to be overbroad, in that they attempt to justify a widely applied rule by appealing only to a relatively small set of contractual scenarios. ${ }^{12}$ Second, most of the extant transaction cost rationales fail to consider the possibility of contract renegotiation. When the parties can renegotiate the terms of the contract, it may be possible for them to "bargain around" the transaction costs that ostensibly necessitate the doctrine. Without a full understanding of the relationship between renegotiation and the Coase theorem, it is difficult to evaluate thoroughly the economic implications of the penalty doctrine.

This note proposes that the penalty doctrine has a special type of bargaining cost justification. Specifically, I argue that the current judicial treatment of stipulated damages may facilitate Coasean transactions by minimizing contract renegotiation costs. Central to this thesis is the observation that contract renegotiation entails a bilateral monopoly market structure, in which neither party competes with an outside "market" to set price. ${ }^{13}$ Furthermore, each party usually possesses some private information about the state of the world (for example, only the promisor knows her best alternative offer, and only the promisee knows his actual damages). This combination of a thin market and private information can impose substantial costs due to strategic behavior, which in turn can frustrate the negotiation process even in the presence of potential gains from trade. The penalty nonenforcement rule, I argue, reduces both parties' incentives and abilities to engage in deceptive behavior during renegotiation, and it thereby mitigates the inefficiencies that usually accompany bilateral monopoly.

Given that bargaining costs significantly affect the efficiency properties of any legal doctrine, ${ }^{14}$ the absence of a negotiation costs analysis in the literature on the liquidated damages rule seems peculiar. While a few scholars note that

cient breach); Paul H. Rubin, Unenforceable Contracts: Penalty Clauses and Specific Performance, 10 J. LEGAL STUD. 237, 238 (1981) (maintaining that penalty enforcement encourages parties to impose externalities on society through publicly subsidized litigation); Lars A. Stole, The Economics of Liquidated Damage Clauses in Contractual Environments with Private Information, 8 J.L. ECON. \& ORG. 582, 583 (1992) (arguing the existence of penalties may signify a defective bargaining procedure); Kathryn E. Spier \& Michael D. Whinston, On the Efficiency of Privately Stipulated Damages for Breach of Contract: Entry Barriers, Reliance, and Renegotiation (Harvard Institute of Economic Research Discussion Paper Number 1649, August, 1993) (on file with the Stanford Law Review) (studying contractual penalties as barriers to entry under a type of renegotiation and when the parties make relationshipspecific investments).

For a more complete analysis of the literature on liquidated damages, see Part II infra.

12. For instance, Clarkson, Miller, and Muris suggest that the penalty doctrine is justified in some contracts where the promisee has a substantial ability to induce breach. See Clarkson et al., supra note 11 , at 368. While such conditions undoubtedly exist for some contracts, it seems doubtful that the promisee frequently has more power than the promisor to induce breach. Moreover, even in such situations, the parties can capture a surplus by renegotiating the terms of the contract to avoid such wasteful expenditures of effort. For a more extended discussion of the Clarkson rationale, see text accompanying notes 76-83 infra.

13. This observation remains valid even if a contract is multilateral. In most cases, each party to a contract has distinct rights and obligations, thus giving her certain monopolistic powers.

14. Law and economics scholars have long recognized that transaction cost reducing rules have a special appeal. Anthony Kronman and Richard Posner argue that a contractual restraint will transcend "mere" paternalism if it serves such a purpose. KRONMAN \& POSNER, supra note 1, at 254. Robert Cooter and Thomas Ulen extend this argument by asserting that facilitating private bargaining is not 
contract renegotiation may play some role in explaining the penalty doctrine, ${ }^{15}$ no one has attempted to analyze the relationship rigorously. ${ }^{16}$ This vacuum in the literature may be partially due to the fact that bilateral bargaining is difficult to analyze. Because bargaining outcomes are often nonunique and processdependent, and because one can never be sure which bargaining "game" the parties would adopt, robust predictions about bargaining outcomes frequently prove elusive.

In order to overcome this analytical dilemma, this note employs a methodological approach from game theory called "mechanism design." This approach enables one to analyze the outcomes of bargaining processes (and other allocation schemes) even when the precise procedures used by the parties are unclear. Although mechanism design techniques have obvious relevance to the study of legal institutions, ${ }^{17}$ and have had a revolutionary effect on microeconomics, ${ }^{18}$ this methodological approach is still somewhat unfamiliar to the legal community. Its introduction, therefore, seems long overdue.

Part I of this note describes the existing common law regime of penalty nonenforcement and sketches the historical emergence of the penalty rule in the case law. Part II examines in greater detail the various law and economics theories regarding the common law regime and argues that these explanations provide neither a convincing critique of the doctrine nor an adequate defense of its existence and persistence. Part III, which constitutes the core of the note, examines contract renegotiation using mechanism design techniques. The results of this analysis appear substantially to vindicate the common law penalty doctrine (especially in what is known as its ex post form ${ }^{19}$ ) as an efficiencyenhancing policy. These conclusions remain valid, and may in fact be stronger, even when courts' alternative measures of damages are imprecise or costly to ascertain. More important, in contrast to many existing theories, these results withstand scrutiny from the Coase theorem, since they focus explicitly on bilateral bargaining costs.

only a normative principle for legal rules, but also a descriptive one. COOTER \& ULEN, supra note 6, at 102.

15. See PosNer, supra note 6, at 116; Goetz \& Scott, supra note 6, at 587.

16. Despite the large literature on stipulated damage clauses, I found only one effort incorporating the prospect of renegotiation, and even then the renegotiation process is modelled in a highly simplified environment. See Spier \& Whinston, supra note 11, at 5 (using a cooperative "Nash" bargaining solution and perfect information).

17. By their very nature, legal institutions serve to allocate legal entitlements among individuals. Whenever those rights that can be "priced" by external markets, the courts are effectively allocation "mechanisms." Mechanism design techniques have been used to model a myriad of allocation institutions. See, e.g., Paul R. Milgrom, Auction Theory, in Advances IN Economic Theory, FifTH WorLd Congress 1 (Truman F. Bewley ed., 1987); J.A. Mirrlees, An Exploration in the Theory of Optimum Income Taxation, 38 REv. Econ. STUD. 175 (1971); Roger B. Myerson \& Mark A. Satterthwaite, Efficient Mechanisms for Bilateral Trading, 29 J. EcoN. THEORY 265 (1983); Thomas R. Palfrey \& Howard Rosenthal, Voter Participation and Strategic Uncertainty, 79 AM. PoL. SCI. REv. 62 (1985).

18. See, e.g., Drew Fudenberg \& JEAN TIRole, Game Theory 243 (1991) (noting the pervasiveness of the technique in the microeconomics literature).

19. See text accompanying note 27 infra. 


\section{The History and Current State of the Common Law Rule}

The rule disfavoring enforcement of penalties for contractual breach first emerged in the Chancery Court of England. In the sixteenth century, the court began to intervene regularly on behalf of defaulting obligors, relieving them of excessive sums due under penal bonds. ${ }^{20}$ Initially, the Chancery Court granted relief against penal obligations only in cases concerning mortgages, leases, and bonds, and even then only when extreme forfeiture or accidental breach was likely. The scope of the nonenforcement rule expanded in the seventeenth century, when the court established a pattern of refusing to enforce bonds in all contracts, except in circumstances where the level of damages was difficult to ascertain. ${ }^{21}$ The English common law courts followed suit in the late seventeenth century, granting defaulting obligors a perpetual imparlance (i.e., an effective permanent continuance) unless the plaintiff accepted compensatory damages and waived the balance of the penal sum. A series of statutes codified these judicial practices, ${ }^{22}$ and thus regularized the nonenforcement rule in all cases where the amount of the contractual bond exceeded compensatory damages. By the twentieth century, the rule was substantially refined and entrenched throughout the common law world. ${ }^{23}$

The salient rhetorical distinction in the common law rule is whether a stipulated term constitutes a "penalty" (viewed as unenforceable) or a "liquidated damages" provision (viewed as enforceable). ${ }^{24}$ In practice, this characterization ultimately depends on the reasonableness of the contracted sum relative to (1) the damages of the aggrieved party and (2) the difficulty of ascertaining or proving loss. ${ }^{25}$ Despite this formulaic description, the precise contours of the modern penalty doctrine have remained faint. While the rule clearly limits the freedom of (even sophisticated) parties to stipulate damages, "it is not so easy to express in words the exact extent of this limitation."26

The first factor relating to damages is somewhat complex and confused. There are two possible tests for determining whether a damage provision is reasonable in light of the aggrieved party's damages. The first is a precontractual approach, often called the "ex ante" rule, which requires the stipulated sum to be a reasonable forecast of the compensable harm that would result from a breach, as judged at the time of contracting. The second is a postcontractual

20. See A.W.B. Simpson, A History of Common Law of Contract 118-24 (1987). In fact, a version of this rule made earlier, albeit isolated, appearances as far back as the canon law period. Id. at 123.

21. Id. at 120 .

22. Id. at 122 .

23. Id. at 123-24. Note that this was not historically the case in the civil law world. The French Civil Code states that "[w]hen an agreement provides that he who fails to execute it shall pay a sum certain by way of damages, there may not be awarded to the other party a greater or lesser sum." CoDE CIVIL [C. CIV.] art. 1152 (1976). Only a 1975 amendment, which states that "[n]evertheless, the judge may moderate or increase the penalty which has been agreed, if it is manifestly excessive or pitiful," reflects a policy similar to the common law. Id.

24. See, e.g., Dunlop Pneumatic Tyre Co. Ltd. v. New Garage and Motor Co. Ltd., [1915] App. Cas. 79.

25. Restatement (SeCOND) of Contracts $\$ 356 \mathrm{cmt}$. b (1981).

26. 5 Arthur Linton Corbin, Corbin ON Contracts $\$ 1057$ (1964). 
approach, called the "ex post" rule, which compares the actual damages incurred to the stipulated sum, and nullifies the provision if the latter is disproportionately larger than the former. ${ }^{27}$

The second factor relating to ascertainability and proof is more straightforward. As it becomes more difficult for the plaintiff to prove the precise magnitude of his loss, courts become increasingly willing to accept the stipulated term as reasonable. ${ }^{28}$ Such a situation is most likely to occur when the aggrieved party possesses private information about damages, and either the court cannot verify this information, or it can verify the information but only at a substantial cost. ${ }^{29}$

Hence, if the range of prospective damages that a promisee might suffer (viewed from the time of contracting) is relatively large, then courts often give a greater presumption of validity to the provision under an ex ante test, so long as the stipulated sum lies somewhere in that range. Alternatively, if the range and variance of actual damages that the promisee may have suffered (viewed from what is verifiable ex post) is sufficiently large, courts applying an ex post rule would more readily accept stipulated sums in that range. ${ }^{30}$

27. Section 356 of the Restatement is an oft-cited authority in these cases. It states:

(1) Damages for breach by either party may be liquidated in the agreement but only at an amount that is reasonable in the light of the anticipated or actual loss caused by the breach and the difficulties of proof of loss. A term fixing unreasonably large liquidated damages is unenforceable on the grounds of public policy as a penalty.

(2) A term in a bond providing for an amount of money as a penalty for non-occurrence of the condition of the bond is unenforceable on the grounds of public policy to the extent that the amount exceeds the loss caused by such non-occurrence.

Restatement (SECOND) of Contracts $\$ 356$ (1981) (emphasis added).

The Uniform Commercial Code also recognizes both rules:

Damages for breach by either party may be liquidated in the agreement but only at an amount which is reasonable in the light of the anticipated or actual harm caused by the breach, the difficulties of proof of loss, and the inconvenience or nonfeasibility of otherwise obtaining an adequate remedy. A term fixing unreasonably large liquidated damages is void as a penalty.

U.C.C. \& 2-718 (1989) (emphasis added).

A more detailed discussion of the interaction between the ex ante and ex post rules appears below. See text accompanying notes 30-33 infra.

28. Restatement (SeCOND) OF Contracts $\S 356 \mathrm{cmt}$. b (1981).

29. In the theoretical section of this note, I discuss both of these possibilities as potential judicial alternatives to "full enforcement" of stipulated damage clauses. See notes 124-161 infra and accompanying text.

30. While the reporter's notes to $\S 356$ of the Restatement assert that the difficulty of proving damages factors into the reasonability calculus only at the time of contracting, comment $b$ gives a counter-example in which damages that are easily determinable ex post effectively nullify the stipulated term. See note 33 infra. Much of the case law appears to support this view. See, e.g., Yockey v. Horn, 880 F.2d 945, 953 (7th Cir. 1989) ("If the nonbreaching party has suffered no damages whatsoever from the breach, the Restatement suggests that the clause will be unenforceable, no matter how reasonable the estimate of damages was at the time of contracting."); Colonial at Lynnfield, Inc. v. Sloan, 870 F.2d 761,765 (1st Cir. 1989) (finding that a stipulated provision is unenforceable when no loss is sustained as a result of breach); Vines v. Orchard Hills, Inc., 181 Conn. 501, 511, 435 A.2d 1022, 1028 (1980) (noting that " $[t]$ his court has ... refused to enforce an otherwise valid liquidated damages clause upon a finding that no damages whatsoever ensued from the particular breach of contract"); Elkhart v. Lee Constr., 1991 Kan. App. LEXIS 1158, at *6 (Dec. 27, 1991) (quoting comment b); Shapiro v. Grinspoon, 27 Mass. App. Ct. 596, 603, 541 N.E.2d 359, 364 (1989) (holding that when damages are easily ascertainable and fall short of the liquidated amount, the aggrieved party can collect no more than his actual damages); Wassenaar v. Panos, 111 Wis. 2d 518, 532, 331 N.W.2d 357, 364 (1983) (stating that 
Two particularly interesting aspects of the penalty doctrine stand out: the interaction between the ex ante and ex post tests in practice, and the formal asymmetry of the doctrine. Below, I briefly address both of these notions.

\section{A. Interaction of the Ex Ante and Ex Post Tests}

Although most courts articulate both ex ante and ex post considerations, the case law suggests an unsettled relationship between the two tests. Courts may treat the tests as conjunctive or alternative, depending on the facts of the case and the jurisdiction. The following diagram is illustrative:

\section{Figure 1}

Comparison of Tests in Case Law

\begin{tabular}{|c|c|c|}
\hline & Passes Ex Post Test & Fails Ex Post Test \\
\hline $\begin{array}{l}\text { Passes Ex } \\
\text { Ante Test }\end{array}$ & Enforceable & Mixed Bag \\
\hline $\begin{array}{l}\text { Fails Ex } \\
\text { Ante Test }\end{array}$ & Irrelevant & Unenforceable \\
\hline
\end{tabular}

The northeast and southwest quadrants of Figure 1 are relatively uncontroversial. Clearly, any stipulated term that passes both tests is valid, and one that fails both tests is invalid. More interesting questions arise when a provision passes one test but fails the other. Terms failing the ex ante test but satisfying the ex post test, while perhaps theoretically interesting, are largely irrelevant. For such a situation to arise, not only must the state of the world change in a way not contemplated at the time of contracting, but the unanticipated change must transform an ex ante unreasonable term into an ex post reasonable term. Moreover, even if this improbable event were to happen, the parties would have little to gain by challenging the stipulated term. A breaching promisor who managed to nullify the clause would still have to pay roughly the same amount of damages to the promisee, because a court would set the damages at a "reasonable" ex post level in order to satisfy the just compensation principle. ${ }^{31}$

The most interesting scenario arises when a stipulated term is a reasonable forecast ex ante yet turns out to be unreasonable ex post. In such a case, current American law is decidedly mixed. Historically, once a stipulated term passed the ex ante test, actual damages were irrelevant, and the breaching party was liable for the full amount stipulated. ${ }^{32}$ More recent case law, however,

the measure of actual damages significantly affects the court's determination of the reasonableness of the stipulated damage provision).

31. For a discussion of the just compensation principle, see text accompanying notes $48-63$ infra.

32. See, e.g., Priebe \& Sons, Inc. v. United States, 332 U.S. 407, 412 (1947) ("[T]he fact that the damages suffered are shown to be less than the damages contracted for is not fatal. These provisions are to be judged as of the time of making the contract."); Southwest Eng'g Co. v. United States, 341 F.2d 
reveals a discernable trend towards invalidating damage provisions on ex post grounds even if those terms were reasonable ex ante. ${ }^{33}$

\section{B. Underliquidated v. Overliquidated Terms}

Another interesting aspect of the penalty doctrine is its lack of formal symmetry. The rule proscribes principally clauses that are overliquidated (unreasonably large), and not those that are underliquidated (unreasonably small). Although some commentators have speculated that the doctrine could apply equally to both types of stipulated terms, ${ }^{34}$ more modern statements of the law explicitly recognize this lack of symmetry. ${ }^{35}$ Nevertheless, the penalty doctrine's formal asymmetry becomes irrelevant if courts somehow avoid its implications in practice. Courts could do this by invalidating underliquidated

998, 1000, 1003 (8th Cir. 1965) (enforcing liquidated damages term even though it was evident that the promisee suffered no damages); Bethlehem Steel Corp. v. City of Chicago, 234 F. Supp. 726, 729 (N.D. Ill. 1964), aff'd, 350 F.2d 649 (7th Cir. 1965) (holding that, even without proof of any actual damages, ex ante reasonability suffices to uphold stipulated term).

33. See, e.g., Sloan, 870 F.2d at 765 ("If the actual damages tum out to be 'easily ascertainable,' [and] the stipulated sum is unreasonably and grossly disproportionate to the real damages from breach [then] the liquidated damages provision will be deemed unenforceable as a penalty."); Hubbard Business Plaza v. Lincoln Liberty Life Ins. Co., 649 F. Supp 1310, 1316 (D. Nev. 1986) ("In order to prove a liquidated damage clause constitutes a penalty, the challenging party must persuade the court that the liquidated damages are disproportionate to the actual damages sustained by the injured party."); Phillips v. Ben M. Hogan Co., 267 Ark. 1104, 594 S.W.2d 39 (Ct. App. 1980) (stating that damages may be liquidated by parties to a contract, but that the stipulated sums will be deemed a penalty, and will be unenforceable, to the extent that they exceed actual damages); Fifty States Mgmt. Corp. v. Pioneer Auto Parks, Inc., 46 N.Y.2d 573, 415 N.Y.S.2d 800, 389 N.E.2d 113 (1979) (holding that courts should examine liquidated damages provisions to ensure that they are not disproportionate to damages actually suffered); Equitable Lumber Corp. v. IPA Land Dev. Corp., 38 N.Y.2d 516, 381 N.Y.S.2d 49, 344 N.E.2d 391 (1976) (noting that myopic reliance on the ex ante test for contracts involving goods has been abrogated by the UCC); Lind Bldg. Corp. v. Pacific Bellfue Dev., 55 Wash. App. 70, 76, 776 P.2d 977, 981 (1989) (holding that in contrast to the traditional ex ante view, "recent cases display a willingness to take [ex post] factor[s] into account, and to refuse enforcement of the forfeiture if it would result in a large windfall"); $c f$. Yockey v. Hom, 880 F.2d 945, 954 (7th Cir. 1989) (suggesting that the ex post rule trumps ex ante reasonability only in the "extreme case" where the promisee suffers no damages).

The Restatement also presents a clear application of the ex post rule: "If, to take an extreme case, it is clear that no loss at all has occurred, a provision fixing a substantial sum as damages is unenforceable." Restatement (Second) of Contracts $\$ 356 \mathrm{cmt}$. b (1981). The illustration given for this comment is one in which a liquidated term is reasonable ex ante (because of the difficulty in prediction), but for unrelated reasons a material breach causes no damages to the aggrieved party. In this case, the clause is unenforceable. Id.

A notable exception to this trend is California, which by statute constrains courts to adopt solely an ex ante perspective. CAL. Crv. CoDE $\$ 1671$ (West 1985) (stating that a liquidated damages term is presumptively valid "unless the party seeking to invalidate the provision establishes that the provision was unreasonable under the circumstances existing at the time the contract was made") (emphasis added).

34. E.g., CoRbIN, supra note $26, \S \S 1054-1075$.

35. The applicable sections of both the Restatement and the UCC explicitly note their inapplicability to underliquidated claims, suggesting that such terms would be invalid only under a finding of unconscionability. "A term that fixes as damages an amount that is unreasonably small does not come within the rule stated in this Section, but a court may refuse to enforce it as unconscionable . ..." REstatement (SECOND) OF Contracts $\$ 356 \mathrm{cmt}$. d (1981). In a similar vein, $\$ 2-718$ of the UCC states: "A term fixing unreasonably large liquidated damages is void as a penalty." U.C.C. § 2-718 (1989). The Official Comments elaborate: "An unreasonably small amount would be subject to a similar criticism and might be stricken under the section on unconscionable contracts or clauses." Id. cmt. 1. 
provisions in one of two ways. First, they might simply ignore the doctrinal distinction between overliquidated and underliquidated terms. Indeed, on numerous occasions, courts have nullified underliquidated provisions simply by analogizing to the penalty doctrine for overliquidated terms. ${ }^{36}$ While an intriguing possibility, however, the argument that modern courts universally (or even predominantly) disregard the formal asymmetry is far from compelling. ${ }^{37}$

The second way in which courts might invalidate underliquidated terms is through the use of alternative doctrines within contract law. The most notable of these are the unconscionability and failure-of-essential-purpose doctrines, which represent judicial invalidation pursuant to ex ante and ex post concerns, respectively. From an ex ante perspective, underliquidated provisions might be vulnerable to unconscionability challenges. ${ }^{38}$ Bargaining asymmetries and unfair or confusing negotiating tactics may give rise to claims of procedural unconscionability, while extremely one-sided contractual terms themselves can give rise to claims of substantive unconscionability. ${ }^{39}$ To prevail on either type of claim, however, a plaintiff must prove more than the mere unreasonability of the disputed term measured at the time of contracting. She must also show either a gross disparity in the values exchanged or evidence of bargaining inequality during contracting. ${ }^{40}$ The penalty doctrine, on the other hand, requires no such additional showing. Moreover, because courts usually view contracts between sophisticated commercial parties as presumptively fair, ${ }^{41}$ plaintiffs

36. See Elizabeth Warren, Formal and Operative Rules Under Common Law and Code, 30 UCLA L. Rev. 898, 903-04 (1983) (finding a "dualistic" approach within the common law, in which some courts adhere to the classical distinction while others analogize to overliquidation cases when determining validity of underliquidated clauses).

37. Id. It is not difficult to find instances where lower courts adhere stingily to the classical asymmetry. See, e.g., Action Orthopedics, Inc. v. Techmedica, Inc., 759 F. Supp. 1566, 1570 (M.D. Fla. 1991) (" $[\mathrm{A}]$ liquidated damages clause is void as a penalty only in regard to the party required to pay, not the payee. Under a liquidated damages clause, a party entitled to receive an amount representing less than his actual damages cannot assert the clause operates as a penalty against him."); Mahoney v. Tingley, 85 Wash. 2d 95, 99-100, 529 P.2d 1068, 1071 (1975) (holding that, except for instances of fraud or overreaching, a promisee is bound by a liquidated damages provision that is unreasonably low); see also Samuel A. Rea, Jr., Efficiency Implications of Penalties and Liquidated Damages, 13 J. LEGAL STUD. 147, 147-48 (1984) (noting the continued practical asymmetry of the rule).

38. See note 35 supra.

39. Procedural unconscionability refers roughly to fault or unfairness in the bargaining process, while substantive unconscionability refers to fault or unfairness in the bargaining outcome. See Melvin Aron Eisenberg, The Bargain Principle and Its Limits, 95 HARv. L. Rev. 741, 752 (1982); Arthur Allen Leff, Unconscionability and the Code-The Emperor's New Clause, 115 U. PA. L. REv. 485, 486-87 (1967).

40. See E. Allen Farnsworth, Contracts $\$ 4.28$ (2d ed. 1990) (citing Williams v. WalkerThomas Furniture Co., 350 F.2d 445, 449 (D.C. Cir. 1965)). The combination of substantive and procedural unconscionability is a sufficient condition to invoke the unconscionability doctrine. Whether either type is also necessary is another question. Professor Farnsworth states that it is "unclear whether substantive unconscionability alone is enough" to invoke the doctrine, and that procedural unconscionability is sufficient alone only if it rises to the level of misrepresentation, duress, or undue burden. Id. The Restatement echoes the view that either alone is sufficient, but only if in extreme magnitude. See Restatement (SECOND) of Contracts § 208 (1981).

A showing of "mere" unequal bargaining power is probably insufficient, however. As comment $d$ of $\$ 208$ states, only severely unequal bargaining power constitutes evidence of lack of meaningful choice, no real alternative, or lack of assent. Id. cmt. d.

41. See, e.g., Tiffany v. Forbes Custom Boats, Inc., 1992 U.S. App. LEXIS 6268 , at $\neq 8$ (4th Cir. Apr. 6, 1992) (holding that a "well-educated, experienced and successful lawyer" could not employ the 
within this classification are unlikely to have unconscionability doctrine available as an underliquidation counterpart to the penalty doctrine (which applies to all parties regardless of sophistication).

When a provision is underliquidated ex post (but not ex ante), unconscionability doctrine is unavailable. ${ }^{42}$ In such cases, courts might still invalidate stipulated terms if the terms fail to meet their essential purpose. ${ }^{43}$ A party making such a claim must demonstrate that conditions have changed so dramatically from those the parties mutually anticipated at the time of contracting that the stipulated provision deprives her of a substantial value of the bargain, ${ }^{44}$ or that it would be exceedingly impractical to carry out the essence of the agreed upon remedy. ${ }^{45}$ While the failure-of-essential-purpose doctrine has been applied successfully to underliquidated damage clauses, ${ }^{46}$ courts can more easily invalidate overliquidated terms under the penalty doctrine, which requires no additional proof beyond unreasonability.

These considerations suggest that the asymmetry of the penalty doctrine has practical as well as doctrinal consequences. While courts potentially can invalidate underliquidated provisions, such maneuvers are much less frequent than the invalidation of overliquidated damages. Since plaintiffs face higher evidentiary hurdles when attempting to invalidate stipulated terms under alternative doctrines, underliquidated terms are relatively impervious to attack unless they are excessively unreasonable.

\section{Approaches in the Law and Economics Literature}

The provocative economic content of the penalty doctrine has spawned numerous justifications and criticisms within the literature. ${ }^{47}$ This Part briefly

unconscionability doctrine to escape contractual waivers); American Casualty Co. v. Federal Deposit Ins. Corp., 944 F.2d 455, 460 (8th Cir. 1991) (denying unconscionability protection for bargain struck by "adult business people"); Gary Wells v. Entre Computer Ctrs., Inc., 915 F.2d 1566 (4th Cir. 1990) (holding that sophisticated franchisees were bound to contractual releases); Continental Airlines, Inc. v. Goodyear Tire \& Rubber Co., 819 F.2d 1519, 1527 (9th Cir. 1987) (holding that "[t]he doctrine of unconscionability cannot be invoked by so sophisticated a party as [the plaintiff]"); Consolidated Data Terminals v. Applied Digital Data Sys., Inc., 708 F.2d 385, 392 n.6 (9th Cir. 1983) (denying unconscionability in absence of material disparity in bargaining power); United States v. Bedford Assocs., 657 F.2d 1300, 1313 (2d Cir. 1981) (finding that a sophisticated commercial development company could not rely upon unconscionability to escape terms of a contract); see also FARNSwORTH, supra note 40, $\$ 4.28$ ("Courts have generally been chary about using the doctrine of unconscionability to protect merchants and similar professionals and have declined to apply the doctrine in favor of sophisticated corporations.") (citation omitted).

42. Unconscionability doctrine hinges solely on information available at the time of contracting. See U.C.C. § 2-302 (1989); FARNswoRTH, supra note 40, § 4.28.

43. Section 2-719 of the UCC articulates the basic failure-of-essential-purpose doctrine, stating: "Where circumstances cause an exclusive or limited remedy to fail of its essential purpose, remedy may be had as provided in this Act." U.C.C. \$ 2-719(2) (1989).

44. E.g., Caterpillar Tractor Co. v. Waterson, 13 Ark. App. 77, 679 S.W.2d 814 (1984); Durfee v. Rod Baxter Imports, 262 N.W.2d 349 (Minn. 1977); General Motors Acceptance Corp. v. Jankowitz, 216 N.J. Super. 313, 523 A.2d 695 (1987). 1983).

45. E.g., Lewis Refrig. Co. v. Sawyer Fruit, Veg. \& Cold Storage Co., 709 F.2d 427 (6th Cir.

46. E.g., Varner v. B.L. Lanier Fruit Co., 370 So. $2 d 61$ (Fla. App. 1979).

47. See notes 6-11 supra and accompanying text. 
reviews the most traditional rationale for the penalty doctrine-the so-called "just compensation" principle-and shows that the possibility of contract renegotiation renders it an inadequate positive theory of nonenforcement. I then focus on the prevailing neoclassical criticisms of the nonenforcement regimethe theories of the efficient insurer and idiosyncratic values-and I suggest that these theories contain problematic shortcomings as well. Finally, I analyze three popular transaction cost economics responses to the neoclassical criticism of the doctrine: moral hazard, contractual externalities, and signaling costs. I argue that, while these responses can describe specific cases in which the doctrine might be justifiable, they often lose their explanatory power when contract renegotiation is possible, and they generally fail to explain the blanket application of the liquidated damages rule.

\section{A. The "Just Compensation" Rationale and Its Detractors}

\section{The just compensation rationale.}

The law of contracts places greater emphasis on efficient outcomes than do other areas of the common law. This focus is rooted in the notion that in a world of completely contingent contracts, ${ }^{48}$ absent externalities or market failures, the economic aim of contract law is simple: enforce all terms of all contracts between rational agents. Indeed, as Steve Shavell has argued, in a world of fully contingent contracts, breach never occurs. ${ }^{49}$ Many, if not most, contracts are executed amid great uncertainty about future states of the world, however. Even though some of these states are more likely to occur than others, the list of possible future states of the world is virtually limitless..$^{50}$ The difficulty and cost of anticipating and providing for each of these future states suggests that completely contingent contracts are infeasible.51 Under these circumstances, contract law can play a significant normative role by "filling the gaps" left by the parties when an unanticipated contingency arises. ${ }^{52}$

48. "Completely contingent contracts" are contracts whose terms spell out the appropriate course of action for every party in every conceivable state of the world. Just like the mythical world of "perfect competition," the world of complete contracts is more of a theoretical construct than an empirical reality. (1980).

49. See Steven Shavell, Damage Measures for Breach of Contract, 11 BELL J. ECON. 466, 467

50. This is especially true of so-called "relational" contracts, in which the buyer and seller must anticipate contingencies far into the future.

51. Oliver Williamson offers several factors that may prohibit fully contingent contracting:

First, not all future contingencies for which adaptations are required can be anticipated at the outset. Second, the appropriate adaptations will not be evident for many contingencies until the circumstances materialize. Third, except as changes in states of the world are unambiguous, hard contracting between autonomous parties may well give rise to veridical disputes when state-contingent claims are made.

Oliver E. Williamson, The Economic Instrtumions of Capitalism: Firms, Markets, Relational Contracting 70 (1985).

52. This view, often labeled "neoclassical contract law," has been around for some time. See, e.g., Oliver Wendell Holmes, The Common law 302-03 (Little, Brown \& Co. 1951) (1881); GordoN TUlLOCK, The LOGIC OF THE LAW 47-48 (1971); Williamson, supra note 51, at 70-71. Ian Ayres and Rob Gertner build further on this point, observing that the structure of default legal rules inevitably affects the degree to which parties make their contracts contingent. See Ian Ayres \& Robert Gertner, Filling Gaps in Incomplete Contracts: An Economic Theory of Default Rules, 99 YALE L.J. 87 (1989); 
The "just compensation" rationale to the penalty doctrine echoes this gapfilling purpose. ${ }^{53}$ Because the stipulated provision may "price" only a subset of future contingencies, unanticipated states of the world can create a disparity between the terms of the contract and the parties' preferences. The potential allocational inefficiencies associated with this disparity may subside when a court can adjust a damage award upon detecting an unanticipated state of the world. 54

To illustrate this point, consider an example from noncooperative game theory: 55 Two agents, player 1 and player 2 , enter into a contract for future performance that will give them each a profit of $\$ 100$ dollars if performed. The contract includes stipulated terms, $D_{1}$ and $D_{2}$, which denote damages to be paid by the respective players should they breach the contract. Furthermore, to reflect uncertainty about the future at the time of contracting, assume that the players learn the state of the world, $\emptyset, 56$ only after entering the contract (but before performance comes due). In different states of the world, the players place differing values on nonperformance of the contract. These values, denoted $v_{1}(\varnothing)$ and $v_{2}(\phi)$ for players 1 and 2 respectively, are known to both players once $\varnothing$ comes about. ${ }^{57}$ Upon learning of the state of the world, each player makes her decision either to perform $\left(P_{i}\right)$ or breach $\left(B_{i}\right)$ the contract $(i=1,2)$. The payoff matrix from this game is as follows:

Ian Ayres \& Robert Gertner, Strategic Contractual Inefficiency and the Optimal Choice of Legal Rules, 101 Y ALE L.J. 729 (1992).

53. The just compensation principle is also deeply rooted in notions of fairness and distributional equity, especially in the realm of liquidated damages. See Alvin C. Brightman, Liquidated Damages, 25 Colum. L. Rev. 277, 302 (1925); Goetz \& Scott, supra note 6, at 561. Because this note analyzes the efficiency dimensions of the penalty doctrine, it does not explicitly consider distributional concerns.

54. My analysis implicitly assumes that expectation damages govern litigation in the relevant contractual disputes. This is largely for convenience, since much of the law and economics literature identifies expectation damages as the best at inducing efficient breach. See Shavell, supra note 49, at 742. A similar analysis is possible under a restitution or reliance damages rule, however.

55. A more theoretical version of this example can be found in Charles Kolstad \& James Leitzel, Efficiency and the Non-enforcement of Penalties (1992) (unpublished manuscript, available at Stanford University Hoover Institution, Working Paper in Economics E-92-2). For an analogous and somewhat less mathematical approach to optimal damage awards, see Barton, supra note 9.

56. The vector $₫$ represents a "list" or a "catalogue" of all the relevant information about the actual state of the world. For instance, if X contracts to mow Y's lawn on Saturday, $\emptyset$ might include information about the weather on Saturday, whether there are any good cultural or sporting events occurring that day, the wealth of each individual, etc. Each of these factors affects the relative attractiveness of contractual performance for one or both of the parties on the day of performance.

57. Alternatively, one could think of these valuation terms are as the players' "outside options." For instance, suppose the contract called for player 1 to sell a widget to player 2 at a future date. For player $1, v_{1}(\phi)$ might be the highest price she could obtain by breaching the contract and selling to someone else. Conversely, player 2's outside option might be the total benefit he would receive by breaching and buying from someone else at a lower price. 
FIGURE 2

\section{Stipulated Damages Contracting Game}

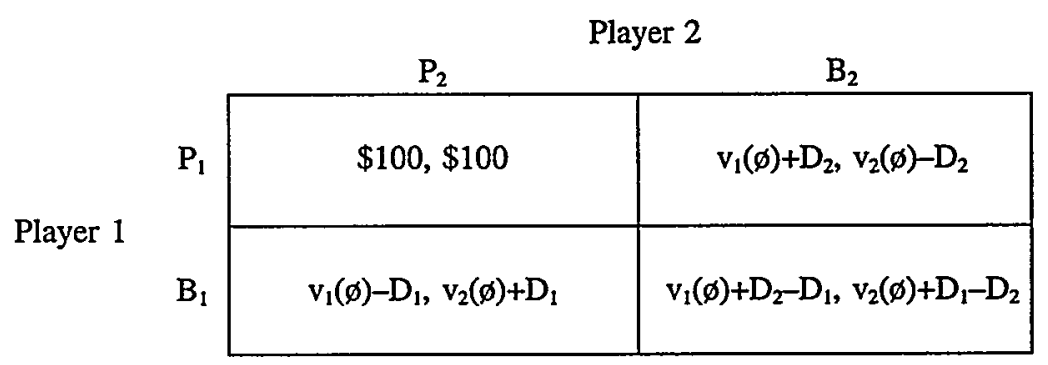

Since each player receives a payoff of $\$ 100$ if both perform, the total social surplus (absent breach) will be $\$ 200.58$ Conversely, if player 1 breaches the contract unilaterally, then she receives a payoff of $v_{1}(\phi)$ but must pay out $D_{1}$, and player 2 receives a payoff $v_{2}(\emptyset)+D_{1}$. A similar analysis exists for unilateral breach by player 2 . Finally, if both players breach the contract, they are still bound by the stipulated clauses. 59

For each contingency $\emptyset$, breach by at least one party is socially efficient when and only when the total social surplus associated with breach, or $v_{1}(\varnothing)+$ $\mathrm{v}_{2}(\varnothing)$, exceeds the total social surplus associated with performance, or $\$ 200.60$ An efficient contract must set the stipulated damage terms $D_{1}$ and $D_{2}$ so as to give each player the incentive to breach if and only if breach is socially efficient. In a world of completely contingent contracts, the parties can always induce efficient breach by making the stipulated terms $D_{1}$ and $D_{2}$ contingent on $\emptyset$. For instance, the contract might stipulate that the breaching party pay the aggrieved party her actual damages sustained from breach; if no damages occur, or if the aggrieved party actually gains from breach, then the party in breach pays nothing. ${ }^{61}$ It turns out that this is an efficient liquidated damages clause, because it induces efficient breach for every state of the world. ${ }^{62} \mathrm{Ra}$ -

58. The assumption that mutual performance yields each party a payoff of $\$ 100$ represents no loss in generality, because it is only the relative payoffs that matter for the players to form strategies. Thus, in modeling games one is always free to choose the payoffs of each player arbitrarily in one cell of the game matrix. Note that, disregarding stipulated terms, if $v_{i}(\emptyset)$ is less than $\$ 100$, then player "i" will incur damages from nonperformance, and if $v_{i}(\varnothing)$ exceeds $\$ 100$, player i gains from nonperformance.

59. This assumption may not be entirely realistic. It is easy to change the model, however, to reflect either no stipulated payments or a third stipulated term when both parties breach. The results of the model are qualitatively no different.

60 . To see this, note that the social surplus if both players perform is $\$ 200(=\$ 100+\$ 100)$, whereas the social surplus if either breaches is $v_{1}(\varnothing)+v_{2}(\varnothing)$. The stipulated damage terms play no efficiency role here, as they are merely transfer payments between the parties.

61. Such a damages provision can be represented as:

$$
\begin{aligned}
& D_{1}^{*}(\varnothing)=\left\{\begin{aligned}
100-v_{2}(\varnothing) & \text { if } v_{2}(\phi) \leq 100 \\
0 & \text { else }
\end{aligned}\right. \\
& D_{2}^{*}(\varnothing)=\left\{\begin{aligned}
100-v_{1}(\varnothing) & \text { if } v_{1}(\emptyset) \leq 100 \\
0 & \text { else }
\end{aligned}\right.
\end{aligned}
$$

62. In order to show this result, consider each of the four relevant cases: (1) $v_{1}(\phi)<\$ 100$ and $v_{2}(\varnothing)<\$ 100 ;(2) v_{1}(\varnothing)<\$ 100$ and $v_{2}(\phi)>\$ 100 ;(3) v_{1}(\phi)>\$ 100$ and $v_{2}(\phi)<\$ 100$; and $(4) v_{1}(\phi)>\$ 100$ and 
tional individuals, when unencumbered by transaction costs or informational asymmetries, would always utilize this type of term. Failing to do so would create a potential surplus that the parties could jointly capture by changing the provisions.

When the costs of writing completely contingent contracts are prohibitive, however, even rational individuals may not be able to stipulate efficient damages provisions. For example, if players 1 and 2 could use only "flat" liquidated damage claims, $D_{1}$ and $D_{2}$, which did not depend on the state of the world, $\varnothing$, then their stipulated provisions might sometimes overshoot actual damages (precluding socially efficient breach), and at other times undershoot actual damages (inducing excessive breach). The just compensation argument suggests that courts intervene in such instances to implement the damages that parties would have agreed to had they contracted for the unexpected contingency. In this sense, the common law penalty rule can be efficiency enhancing.

While this theory is intuitively appealing, it is also far too simplistic. $\mathrm{Nu}$ merous commentators have found this traditional efficiency explanation of the penalty doctrine to be wanting in at least two respects. ${ }^{63}$ First, critics claim that the penalty rule creates gross inefficiencies by preventing individuals with idiosyncratic tastes from obtaining efficient insurance. Second, they argue that in a Coasean world where the parties may renegotiate the terms of the contract, fully enforcing the stipulated term is equally efficient, since the parties will reformulate any inefficient terms.

\section{The efficient insurance critique.}

The first criticism of the just compensation rationale, initially articulated by Professors Goetz and Scott, is essentially one of imperfect monitor-

$v_{2}(\phi)>\$ 100$. In each case, substitute the appropriate damage payment and find the possible Nash equilibria (i.e., all the possible strategies for which each player is maximizing her payoff given the strategies of the other players). It turns out that all the Nash equilibria of the resultant games entail efficient behavior. For example, in case (1), performance by both parties is the efficient outcome, since total social surplus in the event of breach would be less than $\$ 200$. Substituting the optimal damage amounts results in the following payoff matrix:

Comparison of Tests in CASE LAW

Player 2

\begin{tabular}{|c|c|c|}
\hline & $\mathbf{P}_{2}$ & $\mathrm{~B}_{\mathbf{2}}$ \\
\hline $\mathbf{P}_{\mathbf{1}}$ & $\$ 100, \$ 100$ & $\$ 100, v_{1}(\emptyset)+v_{2}(\varnothing)-\$ 100$ \\
\hline$B_{1}$ & $v_{1}(\phi)+v_{2}(\phi)-\$ 100, \$ 100$ & $v_{2}(\phi), v_{1}(\phi)$ \\
\hline
\end{tabular}

Because $v_{1}$ and $v_{2}$ are both less than $\$ 100$, performance of the contract is a "dominant" strategy for each player, and the unique Nash equilibrium is mutual performance, which corresponds to the socially optimal outcome. A similar analysis follows in each of the other cases.

For a more detailed analysis of the intuition, see Barton, supra note 9. For a discussion of Nash equilibria and the concept of a dominant strategy, see DAVID M. KREPS, A CourSE IN MrCroeconomic THEORY 402-10 (1990).

63. See, e.g., Clarkson et al., supra note 11; Goetz \& Scott, supra note 6. 
ing. ${ }^{64}$ They argue that the parties' outside options $\left(v_{1}(\varnothing)\right.$ and $v_{2}(\varnothing)$ in the previous example) vary from case to case, and that a court cannot always ascertain them accurately, even when the parties know their own respective valuations precisely. To the extent that a court must estimate these values in determining damages, promisees with idiosyncratic preferences can suffer under the penalty doctrine. By disallowing full compensation for damages in such instances, the common law rule might induce excessive breach and actually reduce social welfare.

Moreover, Goetz and Scott argue, the doctrine prohibits a promisee with such idiosyncratic tastes from obtaining efficient insurance from the only source capable of providing it: the promisor. She alone has the option to breach or perform. By limiting her downside liability to "reasonable" damages, which are presumptively below those of the idiosyncratic promisee, the penalty doctrine ensures that the promisor will not fully account for the damages caused by her breach. The promisee must therefore attempt to obtain insurance from a third party provider, who will charge a higher premium to reflect the added probability of breach due to the promisor's moral hazard. The difference between the second-party and third-party insurance premia represents the expected inefficiency caused by the penalty doctrine.

Despite its popularity, the Goetz and Scott insurance analysis has a number of limitations. First, their argument applies only in the rare case when the promisee has idiosyncratic preferences. Indeed, if the promisee's valuation of performance were not unreasonably large, he could obtain efficient secondparty insurance from the promisor without fear of subsequent court scrutiny. ${ }^{65}$ Thus, by definition, idiosyncratic tastes are a fairly rare occurrence. Second, even in the rare case where the promisee has idiosyncratic tastes, a large stipulated term may be unnecessary to induce efficient behavior. There is often a competitive spot market for substitute goods or services that the aggrieved party might use to "cover" his position in the event of breach. If there is such a market, then the promisee's damages due to breach are bounded by the loss of bargain associated with having to buy on spot. ${ }^{66}$ The parties need only liquidate this latter amount for efficient second-party insurance to be feasible. ${ }^{67}$

64. See Goetz \& Scott, supra note 6, at 568-77; see also COOTER \& ULEN, supra note 6, at 293-94 (paraphrasing the Goetz \& Scott critique).

65. For promisees with "normal" tastes, an excessively large stipulated damage term is never an efficient second-party insurance contract. Such a contract would overinsure the promisee, thus creating risk. Thus, two rational parties who are either risk neutral or risk averse would likely never enter such a contract. See Rea, supra note 37, at 166; Stole, supra note 11, at 583. For a more complete analysis of optimal risk sharing contracts, see Steven Shavell, Risk Sharing and Incentives in the Principal and Agent Relationship, 10 BELL J. EcoN. 55 (1979), and A. Mitchell Polinsky, Risk Sharing Through Breach of Contract Remedies, 12 J. Legal STud. 427 (1983).

66. For instance, in the oft-cited Goetz and Scott example of a "fanatic fan" who places a high idiosyncratic value on having transportation to a basketball game, the damages he suffers from a breach by the carrier are at most the differences between the original contract price and the price of finding an alternative means of transportation (e.g., a taxi). Notice that the fan's idiosyncratic valuation is immaterial here. See Goetz \& Scott, supra note 6, at 578-82.

67. Goetz and Scott seem to overlook this possibility in their articulation of their "most efficient insurer" model. In the goods market, damages that result from spot market cover are routinely compensable as "reasonable" damages under contract. See, e.g., U.C.C. \$ 2-706 (1989) (allowing a seller to 
Where the promisee has idiosyncratic preferences and the covering spot market is thin, the optimal stipulated damage provision is likely to be "large," reflecting the promisee's subjective tastes. Even so, as the foreseeability rule originating in Hadley v. Baxendale ${ }^{68}$ implies, the stipulated damage clauses would not be void if the promisee's concerns were explicitly spelled out in the contract. Although courts might disallow some subjectively valid damage clauses as unreasonable on account of the uncertain or speculative nature of the subjective valuation, ${ }^{69}$ the common law rule tends to give significant leeway to cases in which damages are "difficult or impossible" to measure. ${ }^{70}$ This suggests that the efficient insurance problem only arises when there is an easy measurement proxy for actual or anticipated damages that differs from the promisee's subjectively high valuation.

Finally, suppose that just such a rare case emerges, where the promisee's tastes are idiosyncratic, no thick substitute spot market exists, but damages (as defined by the court) are not difficult to ascertain. Inefficient breach is not inevitable when multiple third-party insurance contracts are available; the parties may be able to implement a series of third-party transactions that are equivalent to two-party insurance. ${ }^{71}$ If the insurance market is competitive, implying a small bid/ask margin for insurance, then the only added cost is that imposed by writing two third-party insurance contracts instead of one two-party damages contract. ${ }^{72}$ Further, given the rarity of cases in which such an arrangement would be necessary, the expected transaction costs imposed by the penalty doctrine are minimal. Consequently, the efficient insurer criticism is by no means fatal to the "just compensation" rationale for the penalty doctrine.

recover the difference between the contract price and the spot price in the event of buyer breach); id. \$2-712 (allowing a buyer to "cover" her position and recover the difference between contracted cost and spot cost of cover).

One might argue that a reasonability analysis still applies in covering one's position. Indeed, reasonability concerns are even written into the above UCC sections. If markets are sufficiently competitive, however, the reasonability hurdle should not be exceedingly difficult to overcome, as the spot prices should not differ greatly from the contract price. Also, the reasonability hurdle under these sections is probably lower than under the penalty doctrine. Id. \& 2-712 (testing the cover against what was reasonable "under the circumstances"). Finally, even if the reasonability test is the same in both instances, courts will likely realize that loss of bargain damages are necessarily less than the idiosyncratic valuation of the promisee, and will therefore enforce them.

68. 9 Exch. 341 (1854).

69. See Goetz \& Scoth, supra note 6 , at 573 n.53.

70. See text accompanying notes 25-29 supra.

71. Such contracts are easy to imagine. Consider a case in which promisee $X$ has a high idiosyncratic valuation of $\$ 10,000$ for performance, but the penalty doctrine prohibits promisor $Y$ from offering any more than $\$ 1,000$ in liquidated damages. By finding a third party $Z$ who is willing to sell (to $X$ ) and buy (from $Y$ ) a $\$ 9,000$ claim contingent on breach of contract, the contracting parties can still implement full second-party insurance.

I have found no cases ruling on the validity of attempting this type of end run around the penalty doctrine. In the absence of such evidence, I realize that it makes this an unfalsifiable theory. At the same time, however, there appears to be nothing in the Restatement or UCC that specifically prohibits this type of contracting.

72. These added costs are likely to be trivial. The third party holds a perfectly hedged zero-payoff position in this arrangement, and would thus be willing to accept a nominal amount in exchange for his services. 


\section{The Coasean renegotiation critique.}

The second (and perhaps more problematic) critique that Goetz and Scott level at the traditional rationale is that contract renegotiation tends to neutralize the just compensation principle. To take an extreme example, suppose that courts fully enforce all stipulated damage clauses, and that a contingency arises where breach is efficient yet the stipulated term is superoptimal. The Coase theorem suggests that the inaccurate liquidated damages provision need not induce inefficient performance. Rational parties, when faced with such a situation, could renegotiate to capture jointly the surplus created by the contractual inefficiency. As long as bargaining costs are not prohibitive, the parties will implement an efficient allocation through renegotiation regardless of the legal regime. ${ }^{73}$ Hence, in the absence of significant transaction costs or information asymmetries, the notions of efficient breach and just compensation are not completely adequate by themselves to explain the judicial preference for nonenforcement over enforcement.

In sum, neither the "just compensation" rationale nor the efficient insurance critiques provide convincing arguments for or against the liquidated damages rule. Under either full enforcement or the common law rule, the parties can implement quasi-efficient allocations thorugh negotiation. In certain rare instances, where one or both of the parties are outliers with respect to their preferences, it may be more efficient to enforce stipulated terms. These exceptions are of questionable frequency, however, and would not occur at all if both parties could execute multiple third-party insurance contracts. Finally, neither argument addresses the possible asymmetric legal treatment between underliquidated and overliquidated provisions. Thus, any economic advantages or disadvantages to the penalty doctrine must be rooted in the transactional frictions that tend to undo the Coase theorem.

\section{B. Attempted Justifications from Transaction Cost Economics}

The inadequacies of the traditional justifications and criticisms of the penalty doctrine have led numerous scholars to look for possible rationales in transaction cost economics. Since Coase first explored the efficiency neutrality of legal rules absent transaction costs, ${ }^{74}$ the study of these costs has gradually become central to comparative institutional analysis. Not surprisingly, the concept of transaction costs has worked its way into the stipulated damages debate

73. As Professors Goetz and Scott write:

Obstinate insistence on the enforcement of certain penalties may result in a failure to exploit potential efficiency gains by inducing the penalized party not to breach. However, the very existence of such unexploited gains acts as an incentive to the holder of the penalty rights to renegotiate the penalty provision in question.

Goetz \& Scott, supra note 6, at 567-68.

In a game theoretic sense, the prospect of renegotiation allows the promisee to commit not to sue for the original stipulated sum. The Restatement recommends that courts honor such renegotiated changes, under the principles of substituted contracts and accord and satisfaction. RESTATEMENT (SECOND) OF CONTRACTS \$§ 279-281 (1981).

74. See Coase, supra note 1 . 
as well. While the nonenforcement rule may induce more litigation, ${ }^{75}$ it is plausible that a practice of enforcement entails other types of transaction costs. The law and economics literature that attempts to justify the penalty doctrine tends to fit into one of three categories, presented below. The first maintains that problems with opportunistic moral hazard and wasteful effort underlie the common law regime. The second argues that penalty nonenforcement is the optimal institutional response to problems of externalities. The third explores the role of stipulated damage provisions as signaling and screening devices.

\section{Opportunistic behavior and moral hazard.}

A central tenet of welfare economics is that individuals act opportunistically. ${ }^{76}$ Often, this rather pessimistic assumption about human behavior can lead ironically to efficient outcomes. Distorted incentives frequently can and do induce inefficient outcomes, however. When such distortions exist and persist in a market framework, one might expect institutions to arise that mitigate these effects.

The potential problem of opportunistic behavior has not gone unnoticed in the literature. Professors Clarkson, Miller, and Muris aptly point out that in some instances, successful performance by the promisor is partially dependent on the behavior of the promisee. ${ }^{77}$ In these circumstances, an excessively large liquidated damage provision might entice the promisee to collect the penalty by expending socially wasteful effort to induce the promisor to breach. A nonenforcement regime, they argue, is therefore the efficient institutional response. ${ }^{78}$

Despite the popularity of moral hazard arguments in other contexts, the applicability of such an argument to liquidated damage clauses seems misplaced for many reasons. First, it is unlikely that the parties would have written a stipulated clause into a contract that they knew ex ante would be excessive. Moral hazard is problematic, then, only if the stipulated term proves excessive ex post. Even then, while the promisee may attempt to induce breach, the promisor may attempt to ensure performance. The outcome of this tug-of-war depends not only on the liquidated damages transfer, but also on the outside options of the parties and on their respective abilities to effect or avoid breach. As a benchmark case, however, if each player affects the probability of breach symmetrically, and the marginal costs of effort are identical for the two parties, then the player with the highest stake in performance or breach should expend the most effort in procuring her goal. ${ }^{79}$ On average, an increased rate of breach

75. In Part III, infra, I argue that the nonenforcement rule actually induces less litigation and more settlement when the stipulated term is overliquidated or extremely underliquidated.

76. See Williamson, supra note 51, at 64-66 for an interesting discussion of opportunism.

77. Clarkson et al., supra note 11 , at 366-72.

78. The authors proceed to argue, however, that for those contracts in which the moral hazard problem is absent, courts should enforce all stipulated damage terms. See id. at 383-89.

79. This argument is distantly related to the notion that the common law may evolve in an efficient direction even without the help of judges if the litigants' effort is positively related to their personal stake. See John C. Goodman, An Economic Theory of the Evolution of Common Law, 7 J. LeGaL Stud. 393 (1978); George L. Priest, The Common Law Process and the Selection of Efficient Rules, 6 J. Legal Stud. 65 (1977); Paul H. Rubin, Why Is the Common Law Efficient?, 6 J. LeGal Stud. 51 
should occur only in cases where it is more valuable to the promisee than is performance to the promisor. This reasoning suggests that involuntary breach is less likely to occur when breach is inefficient. ${ }^{80}$

Second, because there is apparently no reason to invoke the penalty doctrine for contracts where the promisee has no effect on breach, ${ }^{81}$ the moral hazard justification by itself cannot justify the pervasiveness of the doctrine. At best, this theory is only a partial explanation for the doctrine.

Finally, to the extent that the parties truly face a problem of moral hazard, they could always renegotiate the stipulated damages term to avoid the expected costs of inducing breach or assuring performance. This reasoning should have a familiar ring: Two-party inefficiencies are unlikely to be important if contract renegotiation is possible. ${ }^{82}$ Thus, it is hard to imagine that two informed parties, when considering an unreasonably large liquidated damages provision, will fail to account for moral hazard concerns either initially or through renegotiation. ${ }^{83}$ Without a cogent theory about how bargaining costs interact with moral hazard concerns, the moral hazard rationale skates on rather thin analytical ice.

\section{Diffuse externalities and the common law regime.}

When the participants in an economic transaction do not bear the full social costs of their actions, they may behave in ways that are privately optimal yet socially inefficient, forcing distant third parties involuntarily to subsidize their behavior. When these external costs are sufficiently diffuse, even small transaction costs can destroy the incentive of the affected third parties to bargain with the principals. In such cases, the state may justifiably exercise its institutional power (through laws, taxation, and the like) to ensure that parties internalize these external costs, thereby restoring allocative efficiency. ${ }^{84}$ Some law and economics scholars have posited that the liquidated damages rule is just such an efficient institutional response to the problem of diffuse externalities. ${ }^{85}$ These theories tend to fall into one of two conceptual camps, arguing alternatively that contractual penalties impose diffuse externalities on society by creating either (1) excessive litigation or (2) strategic barriers to entry. ${ }^{86}$

(1977). But see Gillian K. Hadfield, Positive Political Theory and Public Law: Bias in the Evolution of Legal Rules, 80 GEo. L.J. 583 (1992) (critiquing these theories).

80. Note, however, that the effort expended by the parties jointly to induce breach or ensure performance represents a net social cost. If the stakes are large enough, it might be optimal to decline enforcement on this basis alone, even in the absence of inefficient breach/performance.

81. Clarkson et al., supra note 11, at 366.

82. See text accompanying note 73 supra.

83. See Kronman \& Posner, supra note 1, at 224-25; Rea, supra note 37, at 155.

84. See, e.g., COOTER \& ULEN, supra note 6, at 43-52.

85. See Aghion \& Bolton, supra note 11; Brodley \& Ma, supra note 11; Chung, supra note 11; Rubin, supra note 11; Spier \& Whinston, supra note 11 .

86. These theories differ materially from moral hazard models because they apply to contracts that are resistent to renegotiation. By hypothesis, under a diffuse externality, disadvantaged third parties cannot negotiate with the contractual privies. Thus, since the contracting parties alone cannot capture the consequent welfare loss through renegotiation, inefficient behavior may persist. 
The first type of externality argument posits that penalty clauses induce inefficient behavior through subsidized litigation. ${ }^{87}$ Because parties usually do not jointly bear full court expenses, they fail to internalize the entire costs of their litigious behavior. Thus, when a liquidated damage clause provides a potential windfall to the promisee, she might attempt to prove in court that the promisor is in breach when in fact he is not. ${ }^{88}$ The social subsidization of her opportunistic efforts ensures that she will litigate too much. Responding to this problem, courts might refuse to enforce contractual penalties and award the plaintiff only "reasonable" expectation damages instead, thereby removing her incentive to capture the contractual windfall. By following such a rule, the common law regime wipes out the incentives that parties might otherwise have to engage in excessive, frivolous, or wasteful litigation.

Or does it? While appealing, the above argument fails to address satisfactorily why parties would litigate rather than settle. Although the parties do not pay the full costs of litigation, they generally do pay a substantial sum. There is no a priori reason to believe litigation costs are smaller than the costs associated with settlement. If a full enforcement rule were the norm, there would be no uncertainty about the damage amount in case of breach. Full enforcement may therefore increase rather than decrease the chances of settlement, as the parties would be more likely to agree on the "value" of the suit.

Moreover, even under a nonenforcement rule, the parties would export an externality to society when they litigate. The litigation externality theory depends on an assumption that litigating liability under a full enforcement regime is more costly than litigating both liability and damages under a nonenforcement regime. It is not clear which cost is greater, but since breach is often fairly easy to identify, one would expect that the costs would usually cut the other way.

The second, and currently more popular, brand of externality theory argues that penalty clauses may inefficiently restrain competition from third-party buyers or sellers. ${ }^{89}$ When parties contract for future performance, they may foresee a possibility that a third-party "entrant" will attempt to lure one of the them away by offering more attractive terms. If the entrant has sufficient bargaining power, it will tend to act as a price-discriminating monopolist, offering only the minimal amount necessary to lure the relevant party away.

In such instances, the parties to the original contract may have an incentive at the time of contracting to stipulate large damages so that they might jointly "extract" some profit from the potential entrant. While this strategy maximizes their joint payoff from the contract, it necessarily deters a number of producers from entering the market, even though such entry would be socially efficient. 90 Effectively, the stipulated term secures some joint monopoly power for the con-

87. Rubin, supra note 11 , at 241-45.

88. As Williamson writes: "In a world where (at least some) parties are inclined to be opportunistic, whose representations are to be believed?" WILliamson, supra note 51 , at 70 .

89. See Aghion \& Bolton, supra note 11; Brodley \& Ma, supra note 11; Chung, supra note 11; Spier \& Whinston, supra note 11.

90. See Aghion \& Bolton, supra note 11, at 389 . 
tractual privies at the expense of future third-party entrants. ${ }^{91}$ By disallowing such market-foreclosing contractual terms, the penalty doctrine may enhance market efficiency.

This strategic barrier defense of the penalty doctrine seems more sound than the litigation externality explanation. Indeed, in this case the externality that the parties impose on society unambiguously reduces efficiency, and the theory predicts that the parties jointly have strong private incentives to overliquidate. At the same time, however, this approach is incomplete in a number of respects.

First, the theory applies only to settings in which the entrant possesses substantial market power. Indeed, the theory argues that the parties' principal rationale for overliquidating damages is to counteract price discrimination by the entrant. If there is competition among potential entrants, then none would be able to extract significant economic profits even with no penalty clause in the original contract. Consequently, most of the surplus would accrue jointly to the contracting parties, and they no longer would have an incentive to overliquidate the damages term. ${ }^{92}$ Since competitive entry is a plausible (if not likely) scenario, ${ }^{93}$ the strategic barrier theory cannot explain the universal application of the penalty doctrine. Moreover, to the extent that strategic barriers imply anticompetitive behavior, they seem to be more of an apropos target for antitrust law than for contract law. 94

Finally, the strategic barrier argument may not involve a "diffuse" externality at all, and as such, it falls prey to a Coasean criticism similar to the one that plagues the moral hazard theories. ${ }^{95}$ If the parties were allowed to renegotiate the contractual terms upon detecting entry, then it is possible to make all three individuals (i.e., the entrant and the two original privies) better off by altering the stipulated provisions of the contract. ${ }^{96}$ Because the entrant is by definition

91. Id. at 391-92. As Aghion and Bolton note, this externality is exacerbated when the entry market is thin, and the entrant does not have many other outside options. Id. at 396-97.

92. See, e.g., Brodley \& Ma, supra note 11, at 1173 (noting that the Aghion-Bolton approach depends crucially on the assumption that the entrant does not compete with other potential entrants); Spier \& Whinston, supra note 11, at 13 (noting that in the case of a competitive entrant, "the buyer and the seller not only have the incentive to write a socially efficient contract, but also can achieve this goal by using a relatively simple contract that stipulates [ex ante expectation damages] for breach").

93. Brodley and Ma maintain that competitive entry is an unlikely scenario that rarely occurs in practice. Brodley \& Ma, supra note 11, at 1173 . Their argument seems overstated, however. Entrant firms often face at least some potential competition when deciding whether or not to lure a party out of an existing contractual arrangement. So long as the potential competitors have sufficiently similar (but not necessarily identical) valuations/costs, the frontrunning entrant will likely "limit price" its competition out of the market. Doing so may dramatically reduce the economic rents that the entrant can attempt to capture. As a result of this practice, the entry market may appear to be monopolistic when in actuality it is relatively competitive.

94. See id. at 1194-1211 (proposing a theory of enforcement in which strategically overliquidated damages might be attacked using an antitrust rather than a contract approach).

95. See text accompanying notes 76-83 supra.

96. A number of commentators have noted this effect. See, e.g., Spier \& Whinston, supra note 11, at 1-2. But see Brodley \& Ma, supra note 11, at 1176 (noting that renegotiation is unlikely because the contractual penalty sets a "status quo" in favor of the incumbent).

Spier and Whinston conclude that the strategic barrier rationale can survive renegotiation when (1) the original parties make relationship specific investments, (2) the entrant is not competitive, and (3) the entrant possesses most of the bargaining power. Spier \& Whinston, supra note 11, at 13-27. Imposing 
in close proximity to the contractual parties, the transaction costs of joint negotiation are likely to be quite low relative to potential gains.

Thus, the externality theories provide little more than a context-specific justification for the penalty doctrine. While they may apply under certain stylized factual scenarios, they alone cannot explain the uniform application of the rule and are generally not robust to renegotiation possibilities.

\section{Screening, signaling, and stipulated damages.}

In contracts for future performance, the parties often have limited information about their trading partners' characteristics. For example, a supplier of a good might have superior information concerning the quality or reliability of the commodity she sells, while the buyer might have private information about his valuation of the commodity. In such instances, parties may attempt to signal their private information via the stipulated term. Whether the liquidated damages rule inefficiently impedes such signaling, however, remains unclear.

On the one hand, the penalty doctrine is often criticized for prohibiting individuals from signaling their valuations through the terms of the contracts they offer. When sellers or buyers are sufficiently heterogeneous, the quality of the contracted good is uncertain, or the probability of future breach is high, efficiency enhancing transactions may go unrealized under the common law rule. ${ }^{97}$ If courts enforced seemingly punitive liquidated damage terms, the argument goes, parties would be able to signal the quality and reliability of their product to one another, thereby enhancing efficiency. This critique applies especially to new businesses attempting to capture market share. ${ }^{98}$ Since customers are generally unable to monitor the quality of new products, the seller's willingness to incur high downside liability may be enough to increase sales. Such is frequently the case with companies that make guarantees to any dissatisfied customers, as in Carlill v. Carbolic Smoke Ball Co.99

On the other hand, there are persuasive arguments that the penalty doctrine is efficiency-enhancing even when parties wish to signal their quality. In most cases, parties have little reason to signal quality by stipulating damages in $e x$ cess of the promisee's expected damages. ${ }^{100}$ Moreover, some have argued that individuals may have an incentive to signal "too much," thereby distorting the contractual terms so far that disallowing such costly signaling proves more effi-

these conjunctive assumptions, however, narrows the realm of contractual environments to the point where the theory's ability to explain the wide application of the penalty doctrine becomes strained.

97. The classic example of this type of inefficiency is Akerlof's used car (or "lemon") market. See George A. Akerlof, The Market for "Lemons": Quality Uncertainty and the Market Mechanism, 89 Q.J. Econ. 488 (1970).

98. See COOTER \& Ulen, supra note 6, at 295.

99. 1 Q.B. 256 (1893) (allowing customer of company that offered $£ 100$ to anyone contracting influenza subsequent to ingestion of its medicine product to recover on the reward after contracting influenza).

100. Numerous scholars have made this observation. See Timothy J. Muris, Opportunistic Behavior and the Law of Contracts, 65 MENN. L. Rev. 521, 582-84 (1981); Rea, supra note 37, at 157; Stole, supra note 11, at 595. Note, however, that the parties might have an incentive to overliquidate for strategic reasons, in order to exclude potential entrants. See notes 89-91 supra and accompanying text. 
cient. ${ }^{101}$ Judicial intervention via the penalty doctrine can either improve or reduce the efficiency of the contract. ${ }^{102}$ Finally, the possibility of contract renegotiation may nullify the credibility of a quality signal. Signaling and screening rationales therefore appear not to provide unambiguous theoretical support for either side of the penalty doctrine debate.

\section{Summarizing the literature.}

The current law and economics approaches to the penalty doctrine can be summed up as follows: First, the "just compensation" rationale is vulnerable to Coasean critiques and is unconvincing without further investigation into the renegotiation costs imposed by the liquidated damages rule. Second, the "efficient insurer" critique, while theoretically possible, seems rare in practice, and the possibility' of multiple third-party insurance contracts may still allow for efficient insurance regardless of the legal rule. Third, the moral hazard and externality models, while more convincing, fail to explain the pervasiveness and universality of the doctrine and are not robust against renegotiation concerns. At best, they only apply in quite limited circumstances. Fourth, quality signaling through stipulated terms may be efficiency enhancing, but the theoretical results are indeterminate.

Finally, while the transaction costs theories help to explain the prevalence of the ex ante rule, they say very little about its ex post cousin. Even if a stipulated term were reasonable ex ante, it might be common knowledge at the time of performance that the amount is excessive. Courts applying the ex post rule would disfavor even "efficient" signaling provisions if this contingency were to arise. Thus, scholars in law and economics have had limited success explaining the presence and continued apparent vitality of the ex post version of the penalty doctrine. With these problems in mind, I now turn to a possible explanation of the doctrine as a device for minimizing renegotiation costs.

\section{Ex Post Bargaining Costs and the Common Law Regime: An Alternative Approach}

As noted in the previous Part, a principal shortcoming of many of the extant explanations of the penalty doctrine is that they are vulnerable to critiques by the Coase theorem. Namely, they fail to account explicitly for the likelihood and costs of "ex post bargaining," or renegotiation.

When bargaining costs are small, many economic rationales for the doctrine seem no longer compelling, and in fact the legal rule may be largely irrelevant. When the costs of bargaining become relatively large, however, one would expect a nonenforcement policy to dominate an enforcement policy on efficiency grounds.

This Part argues that the liquidated damages rule can mitigate bilateral renegotiation costs, thus increasing the likelihood that the parties will capture

101. See Aghion \& Hermalin, supra note 11, at 381-82.

102. See id. at 403-04; Stole, supra note 11, at 599. 
efficiency gains from renegotiation. Explicitly, I argue that because the parties to a contract often possess private information, each has an incentive to misrepresent the value she places on breaching or performing the contract. This misrepresentation can often subvert the successful renegotiation of the contractual terms, leading to inefficient outcomes. Furthermore, legal rules can affect critically the parties' respective incentives to engage in such strategic behavior. By enforcing "moderate" stipulated terms and declining to enforce overliquidated or dramatically underliquidated ones, the court can minimize the inefficiencies attributable to private information in bargaining. I demonstrate this argument not by using a specific bargaining procedure, but rather by using a relatively recent development in game theory called "mechanism design." This methodology reveals that the set of plausible outcomes that would come from rational bargaining generally entails a lower efficiency cost when courts adopt a penalty nonenforcement policy.

The parties to a bilateral contract face the ultimate thin market for renegotiating disputed terms: a bilateral monopoly. Neither the plaintiff nor the defendant faces competition with others to purchase or sell the legal claim to damages. Consequently, the parties will find it rational to balance their countervailing interests when making offers while bargaining. They will always set their bids and offers at the level where the marginal expected benefit of capturing a larger portion of the surplus equals the marginal expected cost of delay and/or bargaining failure. ${ }^{103}$ As a consequence of such strategic posturing, negotiations may fail, preventing the parties from capturing potential gains unless the "pie" is large relative to the plausible range of private valuations. ${ }^{104}$

Bilateral negotiation is rarely studied rigorously in the law and economics literature on liquidated damages. The infinite number of bargaining games that one might use to model such a negotiation, ${ }^{105}$ the private information of the parties, and the consequences of failed bargaining all add to the difficulty of developing a robust model of bargaining in the shadow of the law. Unlike a simple bilateral bargaining paradigm, where negotiation failure means that the parties each receive a zero payoff, if negotiation fails in a legal context, the plaintiff has the option of litigating the matter in court. The parties' reservation (1988).

103. For a simple example, see Jean Tirole, The Theory of Industrial Organization 22-24

104. Professors Chatterjee and Samuelson provide an oft-cited example of this phenomenon. They study a bargaining game in which the seller and buyer each make a simultaneous offer for the purchase price of a good. The players' private valuations ( $v_{s}$ and $v_{b}$ respectively) are assumed to be private information, each uniformly distributed between 0 and $V$. A transaction occurs only if the seller's bid, s, is slightly greater than the buyer's bid, b, with the actual sales price being the "split the difference" average of the two bids. The authors find that a transaction occurs only if the seller's private valuation exceeds the buyer's by at least V/4. Kalyan Chatterjee \& William Samuelson, Bargaining Under Incomplete Information, 31 Op. REs. 835 (1983). For a comprehensive survey of the extant literature regarding strategic barriers to bilateral negotiation, see John Kennan \& Robert Wilson, Bargaining with Private Information, 31 J. EcoN. LrT. 45 (1993).

105. Examples of specific bargaining structures abound in the literature. See, e.g., Chatterjee \& Samuelson, supra note 104 (analyzing "double auction" bargaining structures); Ariel Rubinstein, Perfect Equilibrium in a Bargaining Model, 50 ECONOMETRICA 97 (1982) (analyzing an "alternating offer" bargaining structure). 
utilities (or BATNAs ${ }^{106}$ ) thus may depend on their private valuations, the legal regime, the magnitude of the stipulated damages amount, and the litigation costs that would be incurred. These problems make any quantification of "strategic bargaining costs" derived from a specific bargaining procedure of questionable value when there is substantial heterogeneity in the types of bargaining procedures used in practice.

Because of this indeterminacy, it is often more fruitful to analyze not the outcome of a particular bargaining procedure, but rather the set of outcomes obtainable from all types of negotiation procedures that rational parties might employ. If any definitive conclusions about this set of outcomes are possible, then those conclusions must hold true for procedures comprising the set.

\section{A. Mechanism Design and the Revelation Principle}

Over the last decade, a number of game theorists and economists have developed a novel method for studying problems of information asymmetries. ${ }^{107}$ This method, known broadly in the literature as the "mechanism design" technique, lends itself well to the study of strategic bargaining in legal contexts. Applying this technique to bargaining problems, one can characterize the costs associated with strategic behavior for all possible negotiation procedures that the parties might employ.

A mechanism is a decision process that allocates goods and transfer payments among a number of agents. ${ }^{108}$ Under a generic mechanism, agents simultaneously report their private valuations to a disinterested third party (the "mechanism designer"), 109 who then uses a mechanical, commonly known set of decision criteria to allocate goods and transfer payments among the participating agents. ${ }^{110}$ Figure 3 below illustrates the basic sequential structure of a mechanism when there are two agents.

The mechanism designer need not be a human mediator, nor a judge, nor a governmental entity. In fact, since the mechanism designer must credibly commit to follow explicitly and mechanically the set of decision rules established

106. The term "BATNA" is a common acronym in the alternative dispute resolution literature for "Best Alternative To a Negotiated Agreement."

107. Information economics has proven to be an amazingly fertile area of research in economics. For excellent overviews of the theoretical tools and their applications, see KREPS, supra note 62, at 577719, and Eric Rassmussen, Games and Information: An Introduction to Game Theory (1989). For advanced readers interested in a more technical treatment, see FudENBERG \& TIROLE, supra note 18, at 209-310.

108. In the mechanism design literature, parties possessing private information are often called "agents," and the private information each agent possesses is called either her "private valuation" or, more generally, her "type."

109. In most applications of mechanism design, the mechanism designer need not be a disinterested party. A number of applications of mechanism design in fact assume that the designer has a vested interest in the actions of the agent (such as in employer-employee or insurer-insured relationships). In a bargaining context, however, the mechanism designer is most often a third party to the potential transaction.

110. For instance, one such mechanism might be for the provision of a public good, such as a bridge. The messages sent to the mechanism designer are the individuals' private willingness to pay for the bridge. The mechanism designer then decides according to a specific set of rules whether the bridge is to be built and how much to tax or subsidize each individual. See KREPS, supra note 62 at 704-12. 
FIGURE 3

Generic Mechanism with Two Agents

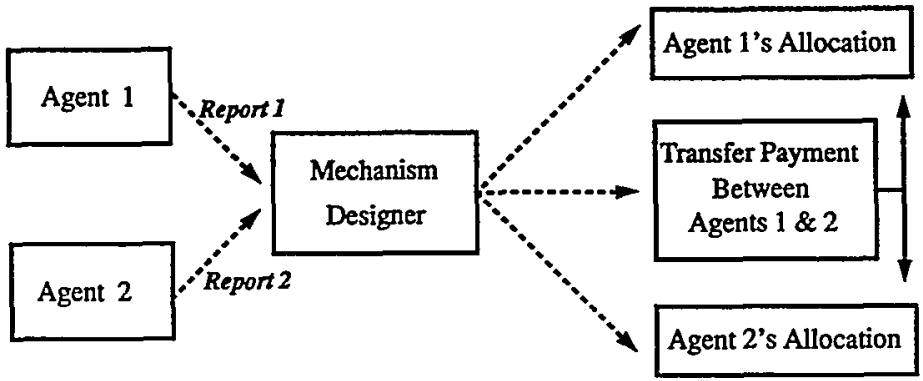

before the agents send their reports, the mechanism designer's role is tantamount to that of a computer or robot.

Mechanisms can be direct or indirect. Under an indirect mechanism, the agents might send any type of signal, while under a direct mechanism, they must send some plausible (but not necessarily honest) report of their private valuations. Hence, where both parties have valuations ranging between $\$ 0$ and $\$ 1$ million, a direct mechanism would not allow the report of "\$3 million," but an indirect mechanism might.

Although the procedures described above seem somewhat awkward, contrived, and unrealistic in an actual bargaining context, the mechanism design framework proves extremely useful in modeling bilateral negotiation. This is because the outcome of any bilateral negotiation procedure is also the outcome of some "equivalent" bargaining mechanism.

To illustrate this point, consider a simple take-it-or-leave-it bilateral bargaining game. In this game, a single seller makes a unilateral price offer, and a single buyer either (1) accepts the offer and pays the demanded amount in exchange for the good, or (2) rejects the offer and both parties "walk away" with no gain or loss. To simplify the analysis, assume that the two parties each have private valuations of the good ( $v_{s}$ for the seller, $v_{b}$ for the buyer) that are independently distributed between $\$ 0$ and $\$ 1$ million with equal probabilityso-called "uniform" distributions. The equilibrium strategy of the seller in this game is to shade her valuation upwards by demanding the average of $\$ 1$ million and her private valuation, or $\left(v_{s}+\$ 1,000,000\right) / 2.11$ The buyer's equilibrium strategy is to accept the seller's offer if it is less than the buyer's valuation $\left(v_{b}\right)$ and to reject it otherwise.

111. The seller's optimal offer $s^{\circ}$ can be calculated in the following way. She wishes to set her offer, $s$, to maximize her expected profits, which are the product of the probability that the buyer's valuation is greater than $s$ and the surplus the seller would gain should $s$ be accepted. Thus, the seller solves:

$$
\operatorname{Max}_{\mathrm{s}}\left(\frac{\$ 1,000,000-\mathrm{s}}{\$ 1,000,000}\right)\left(\mathrm{s}-\mathrm{v}_{\mathrm{s}}\right)
$$

The first order conditions for a maximum set the marginal profit of increasing the price equal to zero, 
A simple bargaining mechanism with the following features yields exactly the same outcome: The seller reports to the mechanism designer her demanded price, and the buyer simultaneously reports the most he would be willing to pay for the good. After receiving these reports, the mechanism designer follows the decision rule that the buyer gets the object only if his report exceeds the seller's, and he pays an amount equal to the seller's demand. Otherwise, nothing happens. The equilibrium outcome of this mechanism is exactly the same as that of the original bargaining game. The seller will demand $\left(v_{s}+\$ 1,000,000\right) / 2$, and the buyer truthfully reports his actual valuation of $v_{b \cdot}{ }^{112}$ Note that any time a transaction takes place at a particular price in the original game, this mechanism also dictates a transaction should take place, and at the identical price.

The above illustration represents a much broader result from game theory that for any bargaining game, there is an "equivalent" mechanism that reaches the same equilibrium outcome. ${ }^{113}$ This result is significant because it allows one to think of any strategic interaction between multiple persons with private information in terms of a mechanism. Since a mechanism has rather standard rules and is easy to describe, it is often more convenient to analyze an equivalent mechanism rather than the strategic situation it represents. Yet, because there are so many different types of plausible bargaining procedures, one might have to consider a myriad of different (direct and indirect) mechanisms before being sure to account for all possible strategic outcomes.

Into this dilemma steps a concept known as the "revelation principle," which is the cornerstone of the mechanism design approach. The revelation principle essentially allows one to focus solely on direct mechanisms in which the parties tell the truth in equilibrium. More precisely, the revelation principle states that for any equilibrium outcome of any mechanism, direct or indirect, there is a corresponding direct mechanism in which (1) truth-telling is optimal

$$
\left(\frac{\$ 1,000,000-\mathrm{s}}{\$ 1,000,000}\right)+\frac{-[\mathrm{s}-\mathrm{v}]}{\$ 1,000,000}=0
$$

which yields the result given in the text. For a variant of this model, see Ian Ayres \& Jennifer Brown, Economic Rationales for Mediation, 80 VA. L. REv. 323 (1994); Joseph Farrell \& Robert Gibbons, Cheap Talk Can Matter in Bargaining, 48 J. ECON. THEORY 221 (1989).

112. To see this, notice first that the buyer's bid does not affect the price he pays for the good, given the seller's price; it can only affect whether or not he buys the good at each possible seller's price. Hence, if the buyer were to shade his report below his actual valuation, there vould be some possible seller demands for which he would have liked to purchase the good, but his bid would preclude him from doing so. Conversely, if he shades his bid upwards, he may get stuck buying the good for more than he values it. Thus, by lying about his valuation, the buyer can never improve his payoff, and in some cases he diminishes it. He will therefore tell the truth.

Knowing that the buyer will report the truth, the seller realizes that the rule the mechanism designer follows replicates exactly the rule that the buyer was following initially in the take-it-or-leave-it game. The seller will receive her asking price so long as it is less than the buyer's actual valuation. Thus, in determining her optimal bid, the seller solves exactly the same problem as in the original game. See note 111 supra.

113. This result remains true as long as the traders have identical time preferences, thus eliminating the possibility of inter-player loans. See, e.g., Fudenderg \& TiROLE, supra note 18, at 290. In what follows, I assume this condition holds; thus, in analyzing the bargaining process followed by the agents, my model does not consider differences in time preferences as a material element of negotiations. 
for all agents, and (2) the outcome is precisely the same as that of the original mechanism. In practical terms, this principle means that it is possible to design a bargaining mechanism where the rules are "rigged" to internalize each party's original equilibrium strategy. This mechanism, therefore, gives both agents an incentive to report their true valuations, and it replicates the payoffs that each agent would have received under the initial bargaining rules.

Despite its seemingly technical language, there is an appealing intuitive interpretation of the revelation principle. Consider a few examples of the revelation principle in action. The best known example is the equivalence of firstprice and second-price sealed bid auctions with risk-neutral bidders. In a firstprice (or "English") auction, the prospective buyers simultaneously submit private bids to the auctioneer. The highest bidder receives the auctioned good and pays her bid in exchange for the good. Under these rules, it is optimal for all the agents to "shade" their bids slightly below their actual valuations, bidding infinitesimally more than the expected level of the next highest valuation.

In a second-price (or "Vickery") auction, the bidding procedure is the same, but the winner pays only the second highest bid rather than her own bid. Under these rules, the agents will find it optimal to bid their true valuations, since one's bid affects only whether one gets the object and not how much she will have to pay.114 More interesting, however, the outcomes of the two auction mechanisms are exactly the same. In either auction, the highest valuer receives the good, and the auctioneer's revenue equals (on average) the expectation of the second highest valuation of the good. The Vickery auction, therefore, exemplifies the revelation principle: It is a direct mechanism in which truth-telling is optimal, and it replicates the outcome of the English auction. ${ }^{115}$

A second example of the revelation principle (this time applied to bargaining) is a rule variation in the take-it-or-leave-it mechanism described above. Recall that the previous mechanism did not involve complete truth-telling; although the buyer truthfully revealed her valuation, reporting $b^{*}=v_{b}$, the seller shaded her private valuation upwards to $\mathrm{s}^{*}=\left(\mathrm{v}_{\mathrm{s}}+\$ 1,000,000\right) / 2 .{ }^{116}$ Suppose now that the mechanism designer adopts different decision criteria, and compares the buyer's bid (b) to an "altered" version of the seller's offer-the average of the seller's offer and $\$ 1,000,000$ (i.e., $(s+\$ 1,000,000) / 2$ ); if the buyer's bid exceeds this amount, then the buyer receives the good at a price equal to the seller's altered bid. Otherwise, nothing happens.

Notice that the only change from the mechanism designer's previous allocation rule is the transformation of the seller's bid from $s$ to $(s+\$ 1,000,000) / 2$. Further, notice that this transformation is identical to the one the seller made in determining her offer in the original game. ${ }^{117}$ Since the new mechanism rules

114. The intuition behind this result is identical to that in the mechanism equivalent to the take-itor-leave-it game: Buyers who shade their valuations can only lower their expected payoffs. See note 112 supra.

115. This insight traces to William Vickery, Counterspeculation, Auctions and Competitive Sealed Tenders, $16 \mathrm{~J}$. FIN. 8 (1961). For a detailed review of auction theory, see Milgrom, supra note 17.

116. See note 111 supra and accompanying text.

117. See note 111 supra and accompanying text. 
now shade the seller's demand in precisely the same way the seller would have originally, and since they do not alter the buyer's bid, truth-telling must now be an equilibrium strategy for both players under the new mechanism.

Essentially, under the altered rules, the mechanism designer simulates how each player would bargain if they in fact had the valuations they reported. If this simulation is exact and credible, neither player has an incentive to lie to the mechanism designer. If a player were to lie, the mechanism designer would play the original game in a way that would misrepresent the interests of the lying agent. Misreporting one's type, then, is tantamount to lying to one's self about private information before entering the negotiation.

An alternative way to conceptualize this point is to imagine that the players cannot bargain face to face but they send trustworthy representatives to the bargaining table in their stead. Because these proxies act in accordance with the interests of the players they represent, the original players have every incentive to reveal their preferences truthfully to the representatives. Once the parties impart this knowledge to the proxies, the actual procedure of bargaining is effectively out of the parties' hands. Similarly, the role of a mechanism designer is mereiy to reproduce this process by playing the role of each parties' trustworthy proxy according to the rules that the parties would have followed. If the mechanism designer is credible in this role, the principal parties must be indifferent between revealing information to the representatives or to the mechanism designer directly; therefore, they have the proper incentives to report the truth to the mechanism designer.

These examples illustrate that the revelation principle allows one to "reprogram" the criteria that the mechanism designer applies so as to replicate the outcome of the original mechanism, but only when the players report their private information truthfully. Note that the revelation principle does not assert that these "truthful revelation" games will be more efficient than the indirect mechanisms they represent but merely that they will entail the same outcome from an efficiency standpoint.

The revelation principle has significant consequences for studying bargaining outcomes. It allows one to concentrate on very simple direct revelation games with truth-telling equilibria, rather than having to examine every mechanism conceivable. Consequently, in characterizing the outcomes of all bilateral monopoly bargaining procedures, we need only examine the set of direct bargaining mechanisms where, regardless of their private valuations, both players (1) find truth-telling optimal and (2) have an incentive to participate in the process. ${ }^{118}$ The mechanism design literature refers to condition (1) as the incentive compatibility (or IC) condition, and to condition (2) as the individual rationality (or IR) condition. ${ }^{119}$ In the next section, I apply this framework explicitly to the problem of renegotiating a stipulated damages clause.

118. This second condition simply states that a mechanism must give both parties at least their BATNAs in equilibrium.

119. Others refer to these two conditions respectively as the "incentive constraint" and the "participation constraint." For additional reading on mechanism design, see, e.g., FuDENBERG \& TrROLE, supra note 18, at 243-318; KREPS, supra note 62 , at 680-97. 


\section{B. Application of the Revelation Principle to Stipulated Damages Renegotiation}

Characterizing the outcomes and the expected bargaining costs from renegotiating a stipulated damages term requires taking into account the form of private information, the timing of the bargaining, and the reservation utilities of the parties. Accordingly, consider the following model, which is a simplified version of the example given in Figure 2: Suppose two risk-neutral parties, a potential plaintiff $(\pi)$ and a potential defendant $(\Delta)$, enter into a contract calling for the defendant to pay the plaintiff the stipulated sum of $\$ D$ if the defendant breaches the contract. To focus on the informational aspects of the problem, assume that only the defendant has the option of breaching or performing the contract. ${ }^{120}$

Upon entering the performance stage of the contract, the parties become aware of private information about the "state of the world." The plaintiff learns about the damages he will suffer because of breach, and the defendant learns about the net gain she will realize from breaching the contract. Let us call the private valuations of the two parties $v_{\pi}$ and $v_{\Delta}$, respectively. Although neither party knows the other's private valuation, assume each knows that the valuations are independently and uniformly distributed between $\$ 0$ and $\$ 1$ million. ${ }^{121}$ Finally, assume that both parties and the court can detect the event of breach with certainty. ${ }^{122}$ In order to focus on prebreach renegotiation, the model below examines only the bilateral bargaining that occurs before the potential defendant makes her decision whether to breach or perform. ${ }^{123}$

Even though the above description fully specifies the parties' preferences, information, and the timing of bargaining, it is not complete unless it considers the players' reservation utilities (or BATNAs). For games of bargaining in the shadow of the law, this can be much more difficult than in other models of bilateral monopoly; if bargaining fails, the legal system gives the defendant an option to "create" a cause of action for the plaintiff (e.g., by breaching the contract), and it gives the plaintiff an option to pursue that cause of action in court. The players' respective choices, and therefore their reservation utilities,

120. This assumption is more reasonable than it looks. Frequently, the state of the world evolves so that one party to a contract wants performance while the other wants to escape from his contractual obligations.

121. Thus, the probability that player $i$ 's private valuation lies between $a$ and $b$ (where $0 \leq a<b \leq$ $\$ 1,000,000)$ equals $(\mathrm{b}-\mathrm{a}) / \$ 1,000,000$.

122. As Paul Rubin points out, litigation over whether breach actually occurred might also be a cause of inefficiency under a full enforcement regime, due to the litigation extemality. See Rubin, supra note 11, at 240-41. In order to focus on the effects of asymmetric information on efficient renegotiation, and because Rubin's analysis does not seem wholly adequate for reasons described in the text following note 88 supra, the analysis below disregards this possibility.

123. There are other possible analyses. For instance, one might examine bargaining after the defendant breaches, but before the plaintiff sues. This note does not analyze this possibility for two reasons: First, if efficient breach is the goal of contract law, then the time of a breach or perform decision is the most relevant from a policy standpoint. Second, the notion of pretrial bargaining (as opposed to prebreach bargaining) has previously been discussed in the literature. See, e.g., Kennan \& Wilson, supra, note 104; Kathryn Spier, Efficient Mechanisms for Pretrial Bargaining (1989) (unpublished manuscript, on file with the Stanford Law Review). 
depend not only on their private information, but also on the value of the stipulated term, the enforcement policy of the court, and the costs of litigation.

A court might adopt any one of a myriad of different enforcement policies when a case comes before it. This note focuses on three such policies, comparing a "full enforcement" rule to two different versions of a "nonenforcement" rule. In one version, the court can detect the exact value of the plaintiff's private valuation; in the other, the court cannot detect such an amount, but must instead make its best "guess."124

Thus, assume that the court may adopt one of three alternative enforcement policies: (1) the full enforcement rule "FE," which mandates that the court award damages equal to the stipulated term $\mathrm{D}$; (2) the exact nonenforcement rule "ENE," which mandates that the court ignore the stipulated term and substitute the plaintiff's actual damages $\left(\mathrm{v}_{\pi}\right)$ in its place; and (3) the noisy nonenforcement rule "NNE," which mandates that the court ignore the stipulated term and substitute a noisy estimate of the plaintiff's actual damages evaluated at the mean value of $\mathrm{v}_{\pi}$ (or $\$ 500,000$ in our case). For simplicity, let the variable $\theta$ denote the applicable legal regime, where $\theta$ can equal $\mathrm{FE}$, ENE, or NNE. 125 Using this notation, the dollar judgement $J_{\theta}$ that the court renders against the defendant is:

$$
\mathrm{J}_{\theta}=\left\{\begin{aligned}
\$ \mathrm{D} & \text { if } \theta=\mathrm{FE} \\
\$ \mathrm{v}_{\pi} & \text { if } \theta=\mathrm{ENE} \\
\$ 500,000 \text { if } \theta & =\mathrm{NNE}
\end{aligned}\right.
$$

Finally, for a given enforcement rule $\theta$, assume each of the parties bears the same litigation costs at trial, denoted $c_{\theta}$ (where $\theta=F E, E N E, N N E$ ). ${ }^{126}$

Given this information, and absent renegotiation, the parties play a game in which the defendant first chooses whether to breach or perform the contract, and if she breaches, the plaintiff decides whether to bring suit. The sequential form of this game (the "game tree") is depicted in Figure 4 below. If the defendant performs the contract, each party receives a (normalized) payoff of zero. If the defendant breaches, but the plaintiff does not sue, the defendant receives and the plaintiff loses their respective private valuations. Finally, if the defendant breaches, and the plaintiff sues, then both players still receive or lose their private valuations; in addition, each must pay her litigation costs, and the defendant also must pay the applicable damages to the prevailing plaintiff.

124. I focus on two types of expectation damages since such measures are widely regarded by economists as more efficient than other court-determined damages. For an excellent discussion of this notion, see Shavell, supra note 49.

125. The NNE rule allows for a type of "judicial incompetence" at trial by assuming that the court cannot determine the actual damages of the plaintiff and must substitute its estimate (presumably the expected value of damages). It is this very inaccuracy that causes Goetz and Scott to write off the notion that renegotiation costs could justify nonenforcement. See Goetz \& Scott, supra note 6, at 587 n.84. As I discuss below, however, many of the conclusions of the model used in this note persist and are even stronger when we allow for such judicial error. See text accompanying notes 154-156 infra.

126. Intuitively, one would expect that it is more costly to litigate both liability and damages than it is to litigate liability alone. However, this need not always be the case. Paul Rubin hypothesizes that litigation costs might be large under full enforcement, especially if the liquidated sum is quite large. See Rubin, supra note 11, at 243. Moreover, the analytical approach presented below is broad enough to incorporate differential litigation costs. 


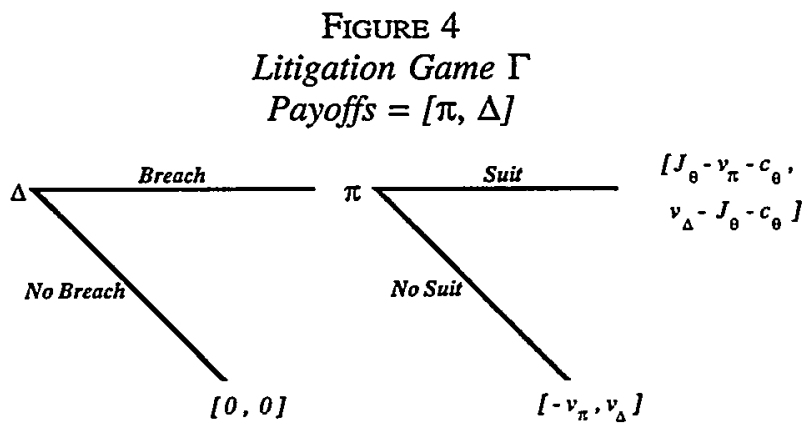

It is important to note that the payoffs in Figure 4 represent the full information expected payoffs for each party. Because private valuations produce informational asymmetries, these payoffs will look different to each player. For instance, along the Breach-No Suit path, the payoffs as seen by the defendant are $\left(-\mathrm{E}\left(\mathrm{v}_{\pi}\right), \mathrm{v}_{\Delta}\right)$, but as seen by the plaintiff they are $\left(-\mathrm{v}_{\pi}, \mathrm{E}\left(\mathrm{v}_{\Delta}\right)\right)$.

We can now analyze the possible outcomes from bargaining "mechanisms" similar to those described above. ${ }^{127}$ Recall that the revelation principle implies that we can limit our attention to mechanisms whose equilibria satisfy the socalled "individual rationality" constraint (both players always participate) and "incentive compatibility" constraint (both players always find truth-telling optimal). ${ }^{128}$

A renegotiation mechanism for contracts, then, is a set of rules by which the mechanism designer uses the players' reports to make two decisions: (1) whether the defendant may breach the contract and (2) how much money she must pay the plaintiff in exchange. Thus, consider a direct mechanism in which the players simultaneously report their respective valuations, $\left(t_{n}, t_{\Delta}\right)$, and in which the mechanism designer uses these reports to make two decisions, $p$ and $s$. The decision rule or "function" $p\left(\mathrm{t}_{\pi}, \mathrm{t}_{\Delta}\right)$ represents the probability of breach given the reports, and $s\left(t_{\pi}, t_{\Delta}\right)$ represents the transfer payment from the defendant to the plaintiff (e.g., "bribe" money in exchange for the probabilistic right to breach). ${ }^{129}$ Let us define the expected gross payoffs (or "utilities") of the players who report $t_{i}$ to the mechanism designer, but whose actual types are $v_{i}$, as $\mu_{i}\left(t_{i} \mid v_{i}\right)$, where i represents $\pi$ or $\Delta$. The expected payoff to the plaintiff $\mu_{\pi}\left(t_{\pi} \mid v_{\pi}\right)$ equals the plaintiff's expected transfer payment less the product of the expected probability of breach and the plaintiff's actual damages. Similarly, the expected payoff for the defendant, $\mu_{\Delta}\left(t_{\Delta} \mid v_{\Delta}\right)$, equals the product of the ex-

127. See text accompanying notes 111-119 supra.

128. The results described below are a summary of the results in Eric Talley, Contract Renegotiation and the Judicial Nonenforcement of Penalties (1993) (unpublished manuscript, on file with the Stanford Law Review). The text of this note presents the intuition behind the specific results, rather than rigorous proofs. The Appendix to this note outlines the general procedure for all the necessary derivations.

129. This type of bargaining mechanism, first developed by Myerson \& Satterthwaite, supra note 17 , is common in the mechanism design literature. For its the application to pretrial negotiation, see Kennan \& Wilson, supra note 104. 
pected probability of breach and the defendant's gain from breach less the expected transfer payment to the plaintiff. ${ }^{130}$

The payoffs defined above are meaningful, however, only in relation to the payoffs the players would receive by simply refusing to bargain. Indeed, the parties will not participate in the bargaining mechanism unless they expect to increase their payoffs. Thus, define the expressions $\mu_{\pi}\left(\mathrm{v}_{\pi}\right)$ and $\mu_{\Delta}\left(\mathrm{v}_{\Delta}\right)$ as the payoffs the players expect playing the noncooperative litigation game $\Gamma$ shown in Figure 4 instead of bargaining. Under the mechanism, then, the expected gain in utility that each player obtains by participating in the bargaining mechanism rather than refusing to bargain is the difference between her gross payoff under the mechanism less her BATNA payoff. Mathematically, we can describe this expected gain as follows:

$$
\begin{aligned}
& \pi^{\prime} \text { s gain } \equiv \mathrm{u}_{\pi}\left(\mathrm{t}_{\pi} \mid \mathrm{v}_{\pi}\right)=\mu_{\pi}\left(\mathrm{t}_{\pi} \mid \mathrm{v}_{\pi}\right)-\mu_{\pi}\left(\mathrm{v}_{\pi}\right) \\
& \Delta^{\prime} s \text { gain } \equiv \mathrm{u}_{\Delta}\left(\mathrm{t}_{\Delta} \mid \mathrm{v}_{\Delta}\right)=\mu_{\Delta}\left(\mathrm{t}_{\Delta} \mid \mathrm{v}_{\Delta}\right)-\mu_{\Delta}\left(\mathrm{v}_{\Delta}\right)
\end{aligned}
$$

From these definitions, one can describe the set of "incentive compatible" and "individually rational" bargaining outcomes from renegotiation. Any such bargaining mechanism must satisfy four distinct conditions: two incentive compatibility conditions (denoted $\mathrm{IC}_{\pi}$ and $\mathrm{IC}_{\Delta}$, respectively), which state that reporting one's true private valuation gives each player a payoff that is at least as good as what she could get by lying about her valuation; and two individual rationality conditions (denoted $\mathrm{IR}_{\pi}$ and $\mathrm{IR}_{\Delta}$, respectively), which state that each player, regardless of her private valuation, does at least as well by participating in the bargaining mechanism as she would do by refusing to bargain and playing the noncooperative litigation game $\Gamma$ instead. In mathematical form, any direct bilateral renegotiation mechanism between the players must satisfy the following inequalities:
(IC $) \quad u_{\pi}\left(v_{\pi} \mid v_{\pi}\right) \geq u_{\pi}\left(t_{\pi} \mid v_{\pi}\right)$ for all $0 \leq t_{\pi} \leq \$ 1,000,000$ and $0 \leq v_{\pi} \leq \$ 1,000,000$
$\left(\mathrm{IC}_{\Delta}\right) \quad \mathrm{u}_{\Delta}\left(\mathrm{v}_{\Delta} \mid \mathrm{v}_{\Delta}\right) \geq \mathrm{u}_{\Delta}\left(\mathrm{t}_{\Delta} \mid \mathrm{v}_{\Delta}\right)$ for all $0 \leq \mathrm{t}_{\Delta} \leq \$ 1,000,000$ and $0 \leq \mathrm{v}_{\Delta} \leq \$ 1,000,000$
$\left(\mathrm{IR}_{\pi}\right) \quad \mathrm{u}_{\pi}\left(\mathrm{v}_{\pi} \mid \mathrm{v}_{\pi}\right) \geq 0$ for all $0 \leq \mathrm{v}_{\pi} \leq \$ 1,000,000$
$\left(I_{\Delta}\right) \quad u_{\Delta}\left(v_{\Delta} \mid v_{\Delta}\right) \geq 0$ for all $0 \leq v_{\Delta} \leq \$ 1,000,000$

Because of the revelation principle, the set of decision rules $p$ and $s$ that satisfy these four conditions represents all possible outcomes from any rational renegotiation effort between the plaintiff and defendant.

130. Mathematically, $\mu_{\pi}\left(t_{\pi} \mid v_{\pi}\right)$ and $\mu_{\Delta}\left(t_{\Delta} \mid v_{\Delta}\right)$ can be represented as follows:

$$
\begin{aligned}
& \mu_{\pi}\left(t_{\pi} \mid v_{\pi}\right)=E\left\{s\left(t_{\pi}, t_{\Delta}\right)-p\left(t_{\pi}, t_{\Delta}\right) v_{\pi} \mid v_{x}\right\} \\
& \mu_{\Delta}\left(t_{\Delta} \mid v_{\Delta}\right)=E\left\{p\left(t_{\pi}, t_{\Delta}\right) v_{\Delta}-s\left(t_{\pi}, t_{\Delta}\right) \mid v_{\Delta}\right\}
\end{aligned}
$$

where $E\{$.$\} denotes the expectation operator.$

The operator $E$ represents the expected value of a random variable. For instance, suppose the random variable $X$ was the sum of the outcomes from rolling two fair dice. The expectation of $X$, denoted $\mathrm{E}\{\mathrm{X}\}$, is the expected sum of the outcomes, or 7 (the expected outcome from each die is 3.5 , and the rolls are assumed independent). However, if we know that outcome of the first die was a 5 , then we can "condition" the expected outcome on this information. Now, the expected value of $X$ conditioned on the first die rolling a 5 , or $E\{X \mid$ first roll is 5$\}$, is equal to 8.5 (equivalently, $5+3.5$ ). In a similar fashion, each player in the bargaining mechanism conditions her expected payoff on the private information that she knows. 
One of the principal aims of contract law is to promote efficient breach of contract. ${ }^{131}$ Hence, a legal rule that allows the parties to renegotiate the stipulated damage term in order to effect efficient breach is "efficient" in the Coasean sense. ${ }^{132}$ In order to achieve such ex post efficiency in renegotiation, the legal regime must give rise to bargaining mechanisms under which the probability of breach, $p\left(t_{\pi}, t_{\Delta}\right)$, is equal to one if the defendant's (truthfully) reported gains, $t_{\Delta}$, exceed the plaintiff's (truthfully) reported damages, $t_{\pi}$. In other cases, efficiency dictates that the legal regime induce no breach at all. ${ }^{133}$ This condition is nothing more than an efficient breach rule.

Unfortunately, implementing a direct mechanism with truth-telling that also satisfies this efficient breach condition on $p$ is often impossible. In these cases, where efficient bargaining is not possible, it would be helpful to know how inefficient the bilateral monopoly is. In order to address this question, I will utilize a specific notion of "bargaining costs," which asks how much a hypothetical outside party must pay to the parties to induce efficient bargaining. Using this measure, it is possible to compare the relative efficiency of various legal rules.

To analyze the relationship between the legal rule and implied renegotiation costs, I partition the analysis into three subsections. First, I consider the full enforcement (FE) rule in both the absence and the presence of litigation costs. Next, I briefly consider the possible nonenforcement rules (ENE and NNE). Finally, I compare the relative bargaining costs that the various rules impose on the parties.

\section{The full enforcement rule (FE).}

Case (i): Full enforcement with zero litigation costs $\left(c_{F E}=0\right)$. Recall that the full enforcement rule mandates that the court enforce the stipulated term $D$ whenever the defendant breaches the contract and the plaintiff sues. When litigation is costless, it is always a "dominant strategy" for the plaintiff to sue after a breach. ${ }^{134}$ Because he loses his actual damages regardless, the plaintiff can never be worse off by suing to recover $\mathrm{D}$. The defendant, knowing that the plaintiff will behave in this fashion, will only breach if her private gain $\left(\mathrm{v}_{\Delta}\right)$ is at least as large as the stipulated amount $\mathrm{D}$. Combining this behavioral insight with the incentive compatibility and individual rationality conditions yields the following proposition:

131. See text accompanying note 48 supra.

132. In other words, such a rule would allow the parties to implement first-best allocations through renegotiation.

133. Mathematically, ex post efficiency imposes the following condition on $\mathrm{p}$ :

$$
p\left(t_{n}, t_{\Delta}\right)=\left\{\begin{array}{l}
1 \text { if } t_{n}<t_{\Delta} \\
0 \text { else }
\end{array}\right.
$$

134. The term "dominant strategy" refers to a game-theoretic strategy that gives a higher payoff than any other strategy regardless of the opponent's strategy or the state of the world. For instance, in a prisoner's dilemma game, each player receives a higher payoff from defecting than she would from cooperating regardless of whether her opponent chooses to cooperate or defect, even though mutual cooperation would maximize the players' joint payoff. See note 62 supra. 
Proposition 1: Under a rule of full enforcement (FE) with zero litigation costs, regardless of the value of the stipulated term $D$, no bargaining mechanism exists that is incentive compatible, individually rational, and also efficient ex post in the absence of an outside subsidy to the parties.

Essentially, this proposition states that the parties by themselves will not always be able to capture the gains to trade through renegotiation. This is not a surprising result. The presence of asymmetric information necessitates both that there be a bargaining surplus and that the surplus be large enough to overcome the effects of strategic misrepresentation. Hence, when gains to trade are small relative to what the parties would receive absent negotiation, their incentives to misrepresent their private valuations are stronger than their incentives to exploit potential gains to trade.

Additionally, Proposition 1 says players can capture the bargaining surplus under a regime of full enforcement and zero litigation costs only if some hypothetical third party were willing to subsidize the bargaining process. This outsider must be willing to induce the parties to negotiate efficiently by offering them a reward for successfully renegotiating the contract. Effectively, then, the existence of such a "bribe" would increase the players' marginal expected costs of breakdown relative to the marginal expected benefits of "strategic behavior."135

One might describe the required subsidy as the price of efficiency-how much society must "bribe" the parties to reach a first-best negotiated solution.

135. For example, consider the simple take-it-or-leave-it bargaining game discussed earlier, in which the seller made a single demand, and the buyer either accepted or rejected that offer. Recall that this game can be mapped into an equivalent direct revelation mechanism, in which the seller and buyer sent simultaneously their respective offer and bid ( $s$ and $b$ ), and the parties traded if the bid exceeded the offer. In this mechanism, the buyer's equilibrium strategy was to reveal his true private information $\left(b=v_{b}\right)$, and the seller's strategy was to shade her private information upwards $\left(s=\left[\$ 1,000,000+v_{s}\right] / 2\right)$. See text accompanying notes 111-113 supra. Suppose now that an outside source were villing to offer the seller an additional reward (or subsidy) for successful bargaining. If the reward is set correctly, it can exactly counterbalance the seller's incentive to misrepresent her valuation. In this case, when the subsidy equals $(\$ 1,000,000-\mathrm{s}) / 2$, the seller would find it optimal to tell the truth in equilibrium.

To see this, recall that the seller maximized her expected profit in setting s. When she receives an extra subsidy of $(\$ 1,000,000-\mathrm{s}) / 2$ in the event of trade, the seller would now solve:

$$
\operatorname{Max}_{s}\left(\frac{\$ 1,000,000-s}{\$ 1,000,000}\right)\left[s-v_{s}+\frac{\$ 1,000,000-s}{2}\right]
$$

Now, the first order condition defining a maximum is given by:

$$
1 / 2(\$ 1,000,000-s)-\left[s-v_{s}+\frac{\$ 1,000,000-s}{2}\right]=0,
$$

which simplifies to $s=v_{s}$ (i.e., the seller reports her valuation truthfully).

An anecdotal example illustrates the intuition behind this "bargaining subsidy." It is not uncommon to see parents offer their feuding children a nominal monetary inducement to get along with each other (such as a weekly allowance). If the children quarrel, then their allowances are withheld. Each child, then, has an incentive to avoid disagreements with the other so as not to lose the benefit of her allowance. Analogously, the "bargaining subsidy" is the smallest amount of money that would be necessary to ensure that the bargaining will not break down (no matter what private valuations the parties have). 
Thus, the required subsidy is a possible measure of inefficiency (or "bargaining cost") due to asymmetric information in negotiation. ${ }^{136}$

Using this measure of inefficiency, it is possible to determine the relative efficiency of the full enforcement rule as the stipulated amount $D$ changes. Indeed, the value of $D$ that minimizes the necessary subsidy is also the one that minimizes the bargaining inefficiencies due to strategic behavior, and-at least in a Coasean bargaining sense-maximizes efficiency. The diagram below depicts how the required subsidy changes under the full enforcement rule (FE) as D varies.

\section{FIGURE 5}

Bargaining Costs of Legal Regime FE as D Varies (in Millions)

$$
\mathrm{C}_{\mathrm{FE}}=\$ 0
$$

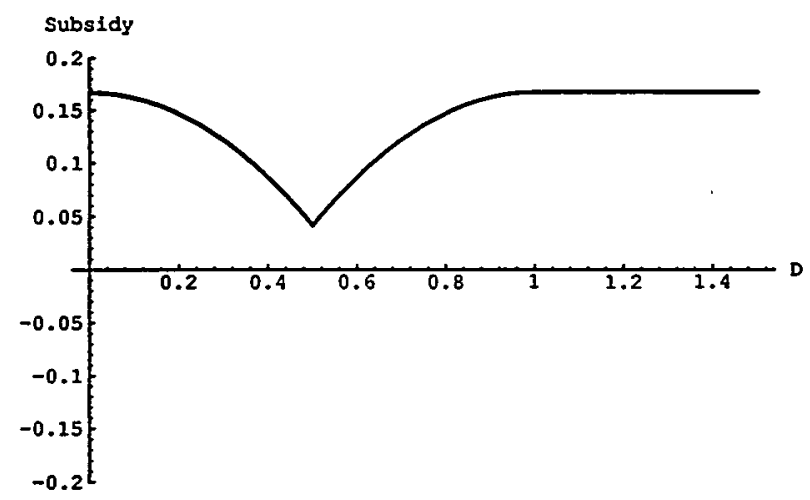

As Figure 5 indicates, when $D=0$, the required subsidy is $\$ 166,667$. As $D$ increases from 0 , the bargaining costs decrease, reaching a minimum value of $\$ 41,667$ when $D=\$ 500,000$. Finally, as $D$ surpasses $\$ 500,000$, the bargaining costs begin to increase, rising back to the original level of $\$ 166,667$ as $D$ reaches $\$ 1$ million. ${ }^{137}$

136. See Spier, supra note 123. This is not the only possible measure of inefficiency. Another candidate is the expected value of lost surplus under a so-called "optimal" bargaining mechanism. Such a mechanism does not always induce efficient breach; rather, it represents the best one can do in designing a bargaining procedure without the aid of outside subsidies. The appropriateness of this measure, however, is dubious. It is unclear why two individuals would ever decide to employ an "optimal" bargaining mechanism when any number of suboptimal ones gives one side or another a greater surplus. In this sense, because there is no "principal" to design the rules of the bargaining game, the fact that the players must "bargain over the mechanism" makes the use of an optimal mechanism somewhat questionable.

137. In algebraic terms, the full enforcement subsidy curve (when litigation costs are zero) is described by the following function:

$$
\text { Subsidy }\left\{\begin{array}{cl}
\$ 166,667- & \text { for } \mathrm{D} \leq \$ 500,000 \\
\$ 2,000,000 & \text { for } \$ 500,000<\mathrm{D} \leq \$ 1,000,000 \\
\$ 166,667-\frac{(\$ 1,000,000-\mathrm{D})^{2}}{2,000,000} & \text { for } \mathrm{D}>\$ 1,000,000
\end{array}\right.
$$


The shape of the FE curve has intuitive appeal. Bargaining inefficiencies occur principally because asymmetric information can lead to strategic misrepresentation of interests and bargaining breakdown. If it were possible to decrease the players' incentives to lie, the probability of breakdown would decrease. Accordingly, the costs of bargaining (as measured by the bargaining subsidy) would decrease as well. This is precisely what happens when D takes on "intermediate" values under the $\mathrm{FE}$ rule.

Suppose, for instance, that $\mathrm{D}$ were greater than $\$ 1$ million. This is the case in which the stipulated term is clearly overliquidated, since the plaintiff's private valuation is always less than or equal to $\$ 1$ million. Further, when there are no litigation costs, the plaintiff will always sue if the defendant breaches. Therefore, absent renegotiation, it is common knowledge that the defendant would never breach when $D$ exceeds $\$ 1$ million, no matter what her valuation. ${ }^{138}$ In a Coasean sense, then, an excessive value of $\mathrm{D}$ grants the plaintiff a de facto "property right" not to have the contract breached, and while bargaining, the plaintiff will assume the role of the "seller" of that right.

Bargaining theory predicts that a seller with private information about the good being sold has an incentive to overstate his private valuation. ${ }^{139}$ Similarly, the plaintiff, as a seller, has an incentive to overstate his damages from breach so as to maximize the surplus he can extract. On the other hand, the defendant, as the buyer of this legal right, has the incentive to understate the value she places on the right to breach. Such distortionary incentives can produce inefficient bargaining breakdowns, making a large subsidy necessary when D equals or surpasses $\$ 1$ million. The bribe (also called "information rent") needed to ensure efficient breach in this region is equal to $\$ 166,667$.

In contrast, if the stipulated term $D$ were set at 0 , the contract would effectively be one of adhesion where the plaintiff waives rights to recover any damages. Compared to the "overliquidated" case, almost everything is reversed. Under a full enforcement rule, the plaintiff gains nothing by suing the defendant after breach. ${ }^{140}$ Knowing this, the defendant will breach regardless of the value of $\mathrm{v}_{\Delta}$, since she will not have to pay the plaintiff any damages. The defendant now owns a de facto property right to breach, thus taking the role of the seller, while the plaintiff assumes the role of the buyer and must purchase the legal right to avoid losing her damages, $\mathrm{v}_{\pi}$. Because of this role reversal, the defendant has an incentive to overstate the outside payoff she receives from

\footnotetext{
A sketch of the derivation is included in the Appendix, infra.
}

138. For those not fully acquainted with game theory, the term common knowledge has a special meaning in the discipline. A fact $X$ is said to be common knowledge if all the players know about $X$, all the players know that each other knows about $\mathrm{X}$, all the players know that each other knows that each other knows $\mathrm{X}$, and so on. When an event is common knowledge, it can never be the case that some player is "fooled" into thinking that some other player is not aware of that fact.

139. This result is quite intuitive and common in the literature. See, e.g., Ayres \& Brown, supra note 111, at 335-51; Peter C. Cramton, Bargaining with Incomplete Information: An Infinite-Horizon Model with Two-Sided Undertainty, 51 REv. ECoN. STud. 579, 581 (1984).

140. More precisely, the plaintiff is at the very least indifferent between suing and not suing. 
breaching, and the plaintiff has the incentive to understate his damages. ${ }^{141}$ Once again, the players misrepresent their private valuations, albeit in the opposite directions, and the costs imposed are just as severe as before $(\$ 166,667$ required subsidy).

Finally, consider the FE rule when D takes on an "intermediate" value, such as $\$ 500,000$. Absent renegotiation, the defendant will breach only when her valuation is greater than $\$ 500,000$, and she will perform when her valuation is below $\$ 500,000$. The plaintiff, on the other hand, desires breach only if his damages are below $\$ 500,000$, and desires performance when his damages are greater than $\$ 500,000$. In this situation, where the legal right is more liabilitylike than property-like, the players cannot always consider themselves buyers or sellers of the right. ${ }^{142}$ Consequently, each party must weigh the payoff associated with overstating her valuation (as she would do qua seller) against the countervailing payoff of understating her valuation (as she would do qua buyer). This tug-of-war between two countervailing incentives effectively restrains the degree of misrepresentation of the players' offers in either direction, reducing the bribe necessary to induce efficient breach. ${ }^{143}$ For this reason, the required subsidy in Figure 5 is lowest when $D$ is $\$ 500,000,144$ the point where the countervailing incentives are the strongest.

Case (ii): Full enforcement with positive litigation costs $\left(c_{F E}>0\right)$. The results so far lack an important element of realism: costly litigation. Indeed, litigation costs can have significant effects on parties' incentives to settle, ${ }^{145}$

141. On first blush, this statement seems counterintuitive. Why would a potential plaintiff ever have an incentive to understate his damages, or a potential defendant to overstate the payoff she gets from breaching? Indeed, in settlement negotiations, this is virtually never the case.

The reason for this ostensibly perverse incentive is that this analysis is not a generic model of "pretrial negotiation." Despite their formal designations, the so-called "plaintiff" has yet to file suit, namely because the so-called "defendant" has yet to commit a breach. By focusing on renegotiation of the contract, then, it is entirely possible that either player could take on the identity of a buyer or seller, depending on the ultimate legal rule imposed. Most of the extant models of pretrial negotiation assume (rather unrealistically) that if bargaining fails, the parties are committed to trial (and paying litigation costs). See, e.g., Spier, supra note 123 . Such assumptions can be problematic, as they imply that simply raising the costs of litigation arbitrarily high can induce efficient bargaining. This cannot be the case, however, because once litigation costs are high enough, the threat to sue is no longer credible. See text accompanying notes 145-150 infra.

142. When a defendant with a "low" valuation (e.g., whose outside option $v_{\Delta}$ is less than $\$ 500,000$ ) encounters a plaintiff with "low" damages, the defendant is a buyer and the plaintiff is a seller. Conversely, when a defendant with a "high" valuation meets a plaintiff with "high" damages, the defendant is a buyer and the plaintiff is a seller.

143. The subject of "countervailing incentives" has only recently begun to receive much attention in the economics literature. It is typically a difficult subject to deal with from a mechanism design standpoint, and general results in such models are rare. See Tracy R. Lewis \& David E.M. Sappington, Countervailing Incentives in Agency Problems, 49 J. Econ. THeORY 294 (1989); Tracy R. Lewis \& David E.M. Sappington, Inflexible Rules in Incentive Problems, 79 AMER. ECON. Rev. 69 (1989); Giovanni Maggi \& Andres Rodríguez, On Countervailing Incentives, - J. EcON. THEORY (forthcoming 1994).

144. When $D=\$ 500,000$ in this "zero cost" case, the bargaining costs as measured by the required subsidy are $\$ 41,667$.

145. In the extreme, litigation costs can produce law suits in which plaintiffs file frivolous suits simply to extract a settlement from a target defendant. Professor Shavell has explored the topic of nuisance suits fairly extensively. See, e.g., Steven Shavell, Suit, Settlement, and Trial: A Theoretical Analysis Under Alternative Methods for the Allocation of Legal Costs, 11 J. LEGAL STud. 55 (1982). 
and, in the context of stipulated damages renegotiation, can affect bargaining behavior in one of two disparate ways. On the one hand, since the parties may incur litigation costs should bargaining fail, they have an incentive to negotiate truthfully and efficiently. On the other hand, the existence of litigation costs often destroys the credibility of a "threat" to sue or breach, making renegotiation more prone to failure. Ultimately, both of these assertions can hold true under the full enforcement rule.

When each player bears litigation costs, the model changes slightly. Now, absent bargaining, the plaintiff will sue if and only if the stipulated damages term exceeds his litigation costs $\left(D \geq c_{\mathrm{FE}}\right)$. Knowing this, a potential defendant will breach either when she knows that the plaintiff will not sue, or when her private gain from breach exceeds the sum of the damages term and litigation costs $\left(v_{\Delta}>D+c_{F E}\right)$. In the presence of litigation costs, the model's predictions become more interesting:

Proposition 2: Under a rule of full enforcement (FE) with positive litigation costs $\left(c_{F E}>0\right)$, an incentive compatible, individually rational, efficient breach mechanism involving no external subsidy exists and is implementable only if $D>c_{F E}$ and $D<\left(\$ 1,000,000-c_{F E}\right)$.

As Proposition 2 suggests, the presence of litigation costs can have either good or bad efficiency implications, depending on their value relative to the stipulated damages term. On the one hand, litigation costs can completely eliminate problems of bargaining inefficiencies by imposing an effective "tax" on bargaining failure. In these cases, the bargaining subsidy is less than or equal to zero, suggesting that the parties can renegotiate the contract and implement efficient outcomes by themselves. On the other hand, when the stipulated term $D$ takes on more extreme values less than $c_{\mathrm{FE}}$, or greater than $(\$ 1,000,000$ $\mathrm{c}_{\mathrm{FE}}$ ), Proposition 2 states that bargaining costs remain at their maximum levels. Figure 6 illustrates this notion for litigation costs of $\$ 100,000$.

FIGURE 6 Bargaining Costs of Legal Regime FE (in Millions)

$$
\mathrm{C}_{\mathrm{FE}}=\$ 100,000
$$

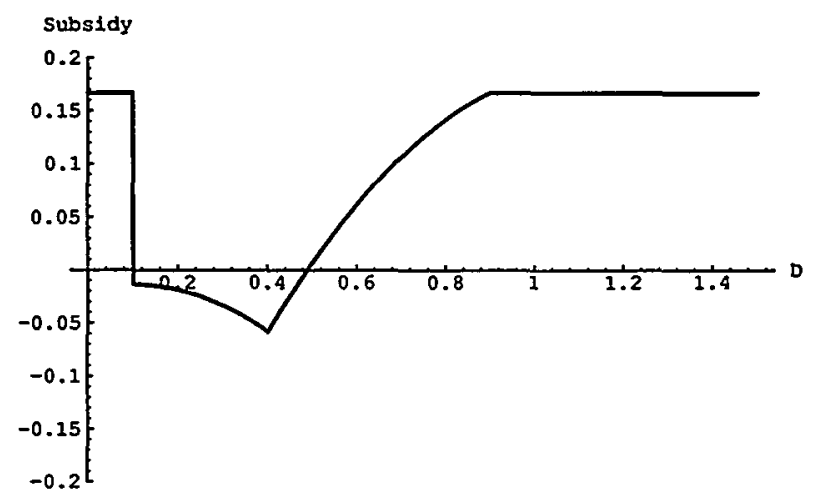


Litigation costs may provide additional incentives for the players to reveal their true preferences by decreasing their expected payoffs should negotiation fail. Note that for some "intermediate" values of D (between $\$ 100,000$ and approximately $\$ 470,000$ in this case), the required subsidy is negative. This implies that there are no bargaining costs whatsoever due to strategic behavior, and thus the parties could bargain in a first-best manner without any third-party bribe. Hence, for intermediate values of $\mathrm{D}$, full enforcement of the liquidated term in conjunction with the presence of litigation costs can induce the efficient bargaining upon which the Coase theorem relies. ${ }^{146}$

Additionally, note that in Figure 6 bargaining costs remain at the maximum level $(\$ 166,667)$ whenever $D$ is between 0 and $\$ 100,000$, or between $\$ 900,000$ and $\$ 1$ million. When $D$ falls in one of these intervals, the specter of litigation costs increases rather than decreases the bilateral bargaining costs. Recall that when $\mathrm{D}$ is less than litigation costs $\mathrm{c}_{\mathrm{FE}}$ (or $\$ 100,000$ in this example), it does not pay for the plaintiff to sue regardless of his actual damages, as he would be giving up more than he would get. In essence, whenever $D$ is less than $c_{\mathrm{FE}}$, the plaintiff's threat to sue loses its credibility. The bargaining costs would thus be similar to the costless litigation case when $\mathrm{D}$ was zero. Conversely, when $\mathrm{D}$ exceeds $\left(\$ 1,000,000-\mathrm{c}_{\mathrm{FE}}\right)$ (or $\$ 900,000$ in this example), it does not pay for the defendant to breach the contract regardless of her valuation, since the plaintiff would simply sue, and the defendant would lose $\left(D+c_{F E}\right)$, which is greater than $\$ 1$ million. Hence, when $\mathrm{D}$ is in this extreme region, the defendant's threat to breach loses its credibility. Reducing the required subsidy is possible only when $\mathrm{D}$ is between $\mathrm{c}_{\mathrm{FE}}$ and $\left(\$ 1,000,000-\mathrm{c}_{\mathrm{FE}}\right)$ (the interval between $\$ 100,000$ and $\$ 900,000$ in this case). ${ }^{147}$

Finally, note from Figure 6 that when $D$ takes on intermediate values around $\$ 500,000$, the curve is not symmetric. When costs are $\$ 100,000$, the region that generates efficient breach (because the required subsidy is negative) lies to the left of $\mathrm{D}=\$ 500,000$. This qualitative asymmetry exists for other values of $\mathrm{C}_{\mathrm{FE}}{ }^{148}$ suggesting that, in the presence of positive litigation costs, the $\mathrm{FE}$

146. The algebraic form of the enforcement subsidy curve with positive litigation costs is described by the following function:

Subsidy $=\left\{\begin{array}{cl}\$ 166,667-\frac{\left(\mathrm{D}+\mathrm{c}_{\mathrm{FE}}\right)^{2}}{\$ 2,000,000}-\frac{\mathrm{c}_{\mathrm{FE}}\left(\$ 1,000,000-\mathrm{D}-\mathrm{c}_{\mathrm{FE}}\right)}{\$ 500,000} & \text { for } \mathrm{D} \leq \mathrm{c}_{\mathrm{FE}} \\ \$ 166,667-\frac{\left(\$ 1,060,000-\mathrm{D}-\mathrm{c}_{\mathrm{FE}}\right)^{2}}{\$ 2,000,000}-\frac{\mathrm{c}_{\mathrm{FE}}\left(\$ 1,000,000-\mathrm{D}-\mathrm{c}_{\mathrm{FE}}\right)}{\$ 500,000} & \text { for } \mathrm{Cax}\left\{\mathrm{c}_{\mathrm{FE}}<\mathrm{D} \leq \$ 500,000-\mathrm{c}_{\mathrm{FE}}\right\}<\mathrm{D} \leq \$ 1,000,000-\mathrm{c}_{\mathrm{FE}} \\ \$ 166,667 & \text { for } \mathrm{D}>\$ 1,000,000-\mathrm{c}_{\mathrm{FE}}\end{array}\right.$

Note, when $c_{F E}=0$, this is the same result as obtained in note 137 supra.

147. Notice that once $c_{\mathrm{FE}}$ exceeds $\$ 500,000$, the interval $\left(c_{\mathrm{FE}}, \$ 1,000,000-c_{\mathrm{FE}}\right)$ collapses to the empty set, as D can never be both greater than $c_{F E}$ and less than $\left(\$ 1,000,000-c_{F E}\right)$. Obviously, then, when $c_{F E}>\$ 500,000$, the bargaining costs equal the maximum of $\$ 166,667$ for any value of $D$.

148. The intuitive explanation behind this result is that in the presence of litigation costs, changes in $\mathrm{D}$ act on the parties in different ways. For instance, if $\mathrm{D}$ grows incrementally from just below $\mathrm{c}_{\mathrm{FE}}$ to just above $c_{\mathrm{FE}}$, all "types" of plaintiff decide to sue, as each can increase his payoff by $\left(\mathrm{D}-\mathrm{c}_{\mathrm{FE}}\right)>0$. The point where all types of plaintiffs shift from not suing to suing corresponds with the discontinuous part of the curve in Figure 5 (at $D=\$ 100,000$ ). 
rule may be better equipped to induce efficient breach when the damage amount is slightly underliquidated than it is when the stipulated term is overliquidated. ${ }^{149}$ Consequently, enforcing underliquidated terms more frequently than overliquidated terms may well be "optimal" from a renegotiation standpoint. ${ }^{150}$

\section{Nonenforcement rules (ENE and NNE).}

Now consider the bargaining costs imposed by the two possible nonenforcement rules (ENE and NNE). Under the "exact nonenforcement" rule (ENE), the court is able to calculate damages with certainty. Hence, it substitutes the plaintiff's actual damages, $\mathrm{v}_{\pi}$, in place of the stipulated term. Under the "noisy nonenforcement" rule (NNE), the court cannot detect damages perfectly, and instead substitutes the expected (or "average") level of the plaintiff's damages ( $\$ 500,000$ for this example) in place of the stipulated term. Note that in both of these rules the court ignores the stipulated term $D$ and substitutes an amount independent of D in its place. ${ }^{151}$

The bargaining costs associated with the noisy nonenforcement rule (NNE) are the easiest to calculate, as they coincide with a point along the full enforcement curve in Figures 5 and 6 above. Because the court always substitutes $\$ 500,000$ for D in this case, the NNE rule is identical to the full enforcement (FE) rule when $\mathrm{D}=\$ 500,000$. For instance, if litigation costs were zero in applying the NNE rule $\left(\mathrm{c}_{\mathrm{NNE}}=0\right)$, the outside subsidy necessary to induce efficient breach is the point associated with $D=\$ 500,000$ in Figure 5 above, or $\$ 41,667$. Similarly, if litigation costs were $\$ 100,000$, as in Figure 6, the bargaining costs associated with the NNE rule would be only $\$ 6,667 .{ }^{152}$

Now, consider the "exact nonenforcement" rule (ENE), in which the court can accurately predict the plaintiff's damages, $\mathrm{v}_{\pi}$, and substitutes that value in

On the other hand, if $D$ shrinks incrementally from just above $\left(\$ 1,000,000-c_{\mathrm{FE}}\right)$ to just below $\left(\$ 1,000,000-c_{F E}\right)$, the defendant's decision to breach depends on her private valuation; only if her private valuation is between $\left(D+c_{\mathrm{FE}}\right)$ and $\$ 1$ million will she breach the contract. Because this is a small proportion compared with the complete switch in strategy in the first case, the bargaining costs change much more slowly for values of $D$ "close" to $\left(\$ 1,000,000-c_{\mathrm{FE}}\right)$ than for values of $D$ close to $\mathrm{c}_{\mathrm{FE}}$.

149. Because I assume the parties' private valuations are uniformly distributed between 0 and $\$ 1$ million, on average, stipulated damage terms of greater than $\$ 500,000$ are likely to be overliquidated, while terms under $\$ 500,000$ are likely to be underliquidated.

150. The exact shape of this asymmetry may be an artifact of my assumption of a uniform distribution of player types. I therefore do not wish to overstate its importance. The discontinuous "jump" at $D=c_{F E}$, however, occurs regardless of the distributional assumptions, so long as those distributions are continuous. See note 148 supra. Furthermore, to the extent that the uniform distribution accurately represents "bounded ignorance" about parties' private valuations, the result is perhaps more justifiable. Nonetheless, it is striking that the asymmetric result emerges from a symmetric distribution, and that the penalty doctrine roughly mimics this result. At the very least, then, this example shows that for some reasonable distributional assumptions, the FE rule imposes incentives to settle that are asymmetric around the mean level of damages.

151. At this point it is important to study the nonenforcement rules as if they were strictly applied (e.g., regardless of the value of D). In the next subsection, I identify the conditions where a court should adopt one rule over another in order to minimize bargaining inefficiencies. The optimal rule in fact depends on the value of $D$.

152. To see this, substitute $c=\$ 100,000$ and $D=\$ 500,000$ into the equation for the full enforcement subsidy given in note 146 supra. 
the place of D. This rule is essentially the classic form of "expectation" damages, in which the plaintiff is put in the position she would have been in had the defendant performed the contract (net any litigation costs). When litigation costs $\left(c_{\mathrm{ENE}}\right)$ are zero, the plaintiff sues regardless of his private valuation and recovers his actual damages. Because the plaintiff is fully "insured" against breach, he gets the same payoff under performance as under breach. Clearly, in this case the plaintiff loses nothing by "stonewalling" in the renegotiation process, even to the point of bargaining failure. Thus, when litigation costs are zero, strategic misrepresentation creates relatively high bargaining costs.

As litigation costs increase from zero under the ENE rule, however, countervailing incentives affect the plaintiff's behavior during bargaining. If bargaining fails, he now must forfeit his litigation costs if he decides to sue, or his damages if litigation costs exceed his damages. Here, the model predicts that bargaining costs decrease as $\mathrm{C}_{\mathrm{ENE}}$ increases from zero. As litigation costs approach $\$ 1$ million, however, the credibility of the plaintiff's threat to sue diminishes. The defendant, knowing that the plaintiff is not likely to sue if his litigation costs are sufficiently high, perceives little danger of litigation should bargaining fail. Thus, for high litigation costs under the NNE rule, it is now the defendant who has the incentive to overstate her private valuation, thereby stonewalling negotiations. Hence, bargaining costs once again increase as the costs of litigation approach $\$ 1$ million.

For both nonenforcement rules, the presence of litigation costs can reduce the parties' incentives to misrepresent their interests, thus also lowering the necessary subsidy. Figure 7 shows the bargaining costs associated with various levels of litigation costs under each of the nonenforcement rules. ${ }^{153}$

Figure 7 suggests that the two types of nonenforcement rules are generally not rankable with respect to the bargaining costs they impose on the parties. For instance, suppose the two rules entail equal litigation costs (i.e., $\mathrm{c}_{\mathrm{ENE}}=\mathrm{c}_{\mathrm{NNE}}=\mathrm{c}$ ). When these costs are low, the NNE rule better exploits the effects of countervailing incentives on the parties. In fact, the NNE rule can implement first-best efficiency when the required subsidy in the NNE curve is zero (this occurs at approximately $c=\$ 166,667$ ). However, when litigation costs are large, the ENE rule entails relatively lower bargaining costs, and it can induce first-best efficient bargaining over a range of relatively high litigation costs. ${ }^{154}$

The nonenforcement rules illustrate two interesting phenomena. First, a "noisy" or untailored damages measure (such as NNE) can outperform a more tailored measure (such as ENE), even if the two measures are equally costly to litigate. As Figure 7 illustrates, when $\mathrm{c}$ is low, the bargaining costs associated with the NNE rule are smaller than those associated with the ENE rule. Second, the ENE rule generally performs better as litigation becomes more costly.

153. Note that the horizontal axis in Figure 7 represents litigation costs, not the stipulated term $D$ as in Figures 5 and 6. The bargaining costs associated with the ENE and NNE rules do not depend on $D$, because under these rules the court by hypothesis ignores the stipulated term in setting damages.

154. In this example, the ENE rule requires a negative subsidy (implying first-best efficiency) whenever $c$ is (approximately) between $\$ 460,000$ and $\$ 900,000$. 


\section{FIGURE 7}

Bargaining Costs of Regimes ENE and NNE as Functions of the

Litigation Costs for $c_{i}, i=E N E, N N E$

(in Millions)

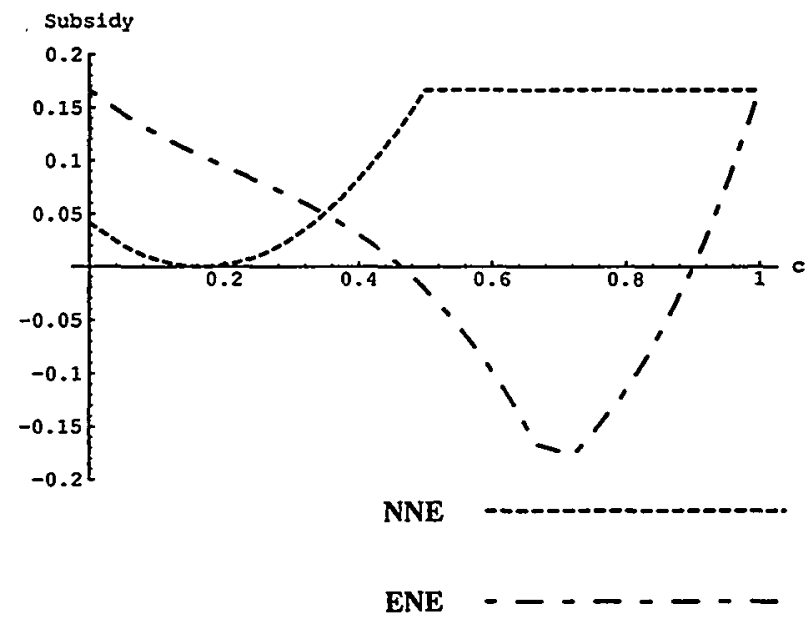

3. Comparison of the full enforcement and nonenforcement rules.

The results of the two previous subsections suggest that the "optimal" judicial policy regarding stipulated damages from a Coasean standpoint may vary with the value of the stipulated term and the respective litigation costs. Two general results stand out: First, when litigation costs are negligible, the noisy nonenforcement rule (NNE) is "optimal" in that it imposes the fewest bargaining costs on the parties. Second, when litigation costs are positive but less than $\$ 1$ million, both nonenforcement rules (ENE and NNE) fare better than the full enforcement rule (FE) for "extreme" liquidated terms, where $D$ is less than $c_{\mathrm{FE}}$, or exceeds $\left(\$ 1,000,000-\mathrm{c}_{\mathrm{FE}}\right)$. These generalizations give rise to the following proposition:

Proposition 3: When litigation costs are zero for all three rules $\left(c_{F E}=c_{E N E}=c_{N N E}=0\right)$, the noisy nonenforcement rule (NNE) minimizes the required subsidy associated with contract renegotiation. Further, when litigation costs are equal for all three rules and are less than $\$ 1,000,000$, the full enforcement rule (FE) imposes the highest bargaining costs on the parties for "extreme" values of $D$ that are less than $c_{F E}$ or greater than $\left(\$ 1,000,000-c_{F E}\right)$.

Figure 8 illustrates the first part of this proposition, plotting the bargaining costs against the size of the stipulated damages term $\mathrm{D}$ when litigation costs are zero for all the possible rules.

Note that the FE curve is the same as that shown in Figure 5. Bounding the FE curve from above is the exact nonenforcement (ENE) line, while bounding the FE curve from below is the NNE line. Both are flat because the value of D 
FIGURE 8

Comparison of FE, ENE, and NNE for $c_{F E}=c_{E N E}=c_{N N E}=0$

(in Millions)
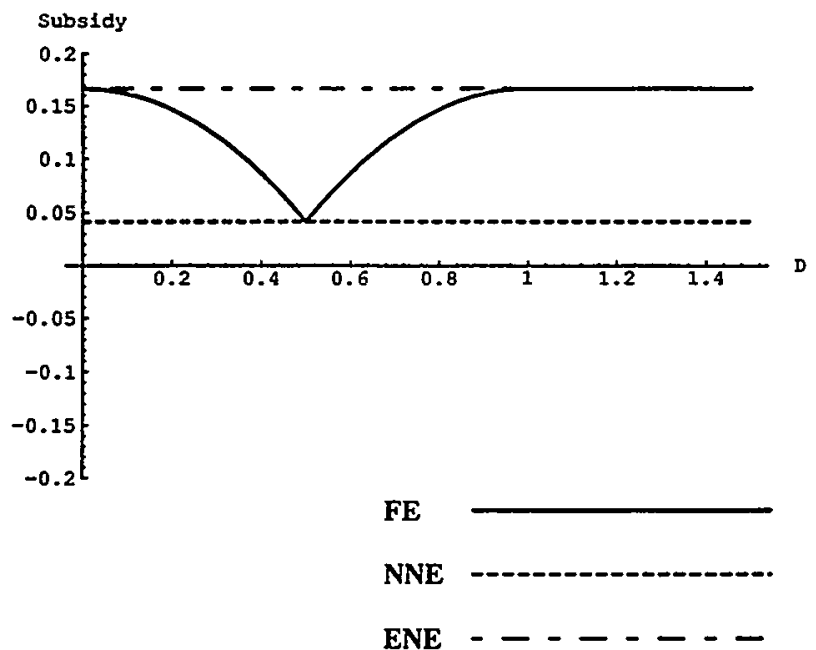

is irrelevant to a court using a nonenforcement rule. ${ }^{155}$ Figure 8 implies that, if litigation costs were zero for all of the rules, the noisy nonenforcement rule would minimize bargaining costs. Since the NNE line corresponds with the FE curve when $D=\$ 500,000$, this is the only value of $D$ for which the FE rule fares as well as the NNE rule. The ENE rule, on the other hand, always produces high bargaining costs when $\mathrm{C}_{\mathrm{ENE}}=0$, for reasons stated above. ${ }^{156}$

Figure 9 illustrates the relationship between the various rules when litigation costs are positive. In this figure, the litigation costs for each rule are set at $\$ 100,000$ for illustrative purposes. Indeed, it is beyond the scope of this note to examine every possible combination of litigation costs. Figure 9, however, embodies a result that holds true for any combination of litigation costs between 0 and $\$ 1$ million: ${ }^{157}$ Fully enforcing "extreme" stipulated damages provisions produces greater bargaining inefficiencies than does either nonenforcement rule.

Notice that in this example the noisy nonenforcement rule (NNE) entails nearly zero bargaining costs, while the exact nonenforcement rule (ENE) imposes greater costs. However, either of these two rules is superior to the full enforcement (FE) rule when the stipulated term is less than $\$ 100,000$, or greater than $\$ 900,000$.

155. The heights of the two nonenforcement lines are in fact the same as their intercepts with the vertical axis in Figure 7, supra.

156. See text accompanying notes 152-153 supra.

157. Professor Rubin advocates the proposition that litigation costs are relatively higher for the FE rule-especially when $D$ is substantially overliquidated - because the parties spend more money on the question of breach. See Rubin, supra note 11, at 243. This interpretation is easy to incorporate into this framework, but it would not offer substantially different results. 


\section{FIGURE 9}

Comparison of FE, ENE, and NNE for $c_{F E}=c_{E N E}=c_{N N E}=\$ 100,000$

(in Millions)

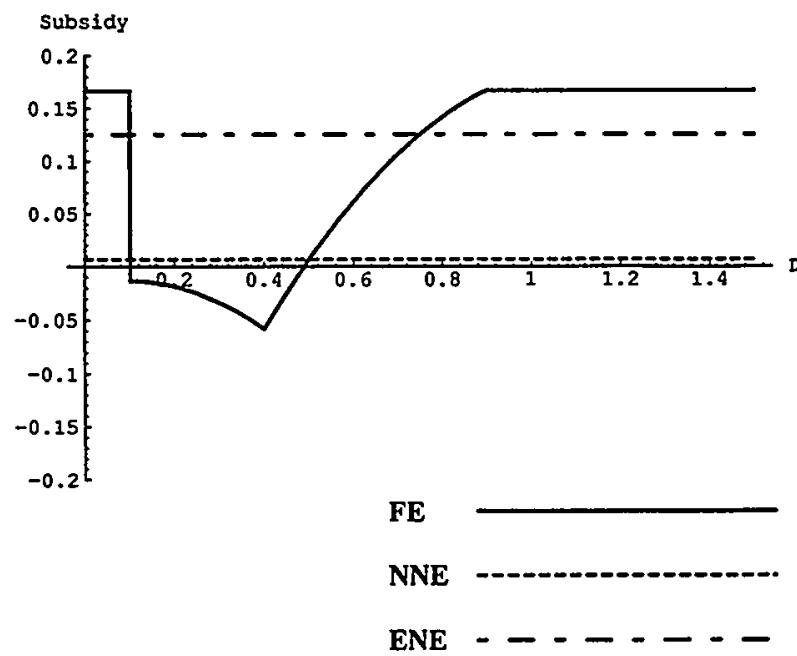

Furthermore, the asymmetric shape of the full enforcement curve in Figure 9 causes it to intersect both nonenforcement curves to the left of the point where $D$ is "clearly overliquidated" (i.e., where $D \geq \$ 900,000$ ). This suggests that courts interested in minimizing renegotiation costs should refuse to enforce even mildly overliquidated stipulated terms, but uphold their mildly underliquidated counterparts.

\section{Results in perspective.}

These results provide a nontrivial exception to the Coasean logic that the assignment of legal rights does not affect economic efficiency. ${ }^{158}$ It clearly makes sense to speak of the "optimal" assignment of legal rights if the assignment itself can affect the degree of transaction costs through strategic failures to capture gains from trade.

Taken together, these observations recommend a judicial policy that is remarkably similar to the common law penalty doctrine. Indeed, the doctrinal analysis of Part I indicates that courts apply the doctrine asymmetrically to overliquidated and substantially underliquidated damages claims. ${ }^{159}$ At the very least, the analysis above indicates-contrary to the conclusions of some law and economics scholars ${ }^{160}$ - that the current application of the ex post rule is at least partially grounded in efficiency concerns.

158. See Coase, supra note 1 , at 10; A. Mitchell Polinsky, Introduction to Law and EcoNomics 13 (1983).

159. See text accompanying notes $27-46$ supra. As noted before, Comment b of the Restatement provides for the nonenforcement of "extreme" cases of underliquidation. See note 31 supra.

160. Professor Rea, for instance, concludes that the ex post reasonableness of the damages term is irrelevant from an efficiency standpoint, and that only an ex ante rule is "consistent with economic 
Additionally, the renegotiation model provides a plausible efficiency justification for a nonenforcement policy even when actual damages are ambiguous or costly to determine. Indeed, when litigation is costly, both the more tailored (ENE) rule and the less refined (NNE) rule can impose lower bargaining costs than the full enforcement (FE) rule.

Law and economics scholars frequently have neglected this rationale for the penalty doctrine. For instance, Professors Goetz and Scott only briefly entertained the possibility that renegotiation costs may impede Coasean bargaining. Their response?

It could be hypothesized that if the legal rule could be constructed precisely to categorize and enforce only those agreements where renegotiation costs are less than the litigation costs, ex post measurement would be superior. This hypothesis is rejected because such a rule would require numerous factual considerations, and would necessarily be relatively imprecise . . . . 161

As this excerpt suggests, it is commonplace for scholars to discount the value of a judicial rule when it is either inaccurate or costly to administer. Contrary to this point of view, the above results illustrate that the very existence of administrative costs and judicial imprecision under a nonenforcement rule may reduce if not eliminate the impediments to efficient Coasean bargaining under a nonenforcement rule.

\section{CONCLUSION}

The common law penalty doctrine has a long and somewhat controversial history, not only in legal treatises and case law, but also in the academic pages of law and economics texts and journals. To the extent that it imposes a constraint on freedom of contract, the doctrine is simply irreconcilable with the zero transaction cost world of neoclassical Coasean economics. In such a world, the "just compensation" principle is no more than a guise for legal paternalism.

Nevertheless, modern economists and lawyers realize that a frictionless economic world never has, nor will, exist in practice. Accordingly, a number of efforts have been made to justify the common law regime from a transaction cost rationale. This note represents another such attempt. Its approach does not suffer from the same shortcoming as do many others, however, because it takes the proverbial Coasean bull by the horns and explicitly examines the bargaining costs that the parties face during renegotiation. In doing so, this theory complements rather than substitutes for the other transaction cost approaches. Since full enforcement impedes renegotiation of contractual penalties, the moral hazard and externality rationales to the doctrine need not be embarrassed by their failure to allow for renegotiation.

Additionally, this analysis isolates a common mistake made by law and economics scholars. It is not always legitimate to favor one legal rule over

theory because enforcement of damage clauses is likely to be efficient when damages are reasonable ex ante but unreasonable ex post." Rea, supra note 37, at 167.

161. Goetz \& Scott, supra note 6, at 587 n.84 (emphasis added). 
another simply because the latter is relatively imprecise and/or more costly to administer. Indeed, those very factors may provide sufficient countervailing incentives for the potential litigants to reach a first-best outcome through bargaining, thus avoiding litigation entirely.

Some might argue that, while the above model gives a plausible rationale for the use of the ex post penalty doctrine, it does not directly address how the rule feeds back on ex ante contracting. This argument has merit, especially when parties can write completely contingent contracts. In a world where it is costly to write such contracts, however, parties at the contracting stage generally prefer to limit their attention to the most probable states of the world, leaving the allocational decision for low probability contingencies to renegotiation. In this sense, a legal rule that minimizes the costs associated with such bargaining would allow the parties to concentrate (efficiently) on high probability states of the world, knowing that they could bargain efficiently should unanticipated contingencies arise. Moreover, since this note complements other transaction cost approaches, suggesting that renegotiation is less likely precisely when a liquidated term constitutes a penalty, it need not provide an independent hypothesis as to why parties would overliquidate damages. ${ }^{162}$

Finally, this note helps place an analytical "public good" within the purview of legal scholarship. Game theoretic techniques of mechanism design can be tremendously useful in studying the role of information asymmetries in an institutional framework, and the law is just such a framework.

In many respects, the above analysis brings us full circle with respect to the penalty doctrine. Indeed, considering renegotiation may well salvage the just compensation principle from the seemingly fatal Coase theorem attack that was a popular theme of a decade ago. To the extent that this approach is successful, common law courts simply articulate the right rule for the wrong reasons.

162. Recall that the model used in this note assumes that contractual terms were already set, and it does not specifically address the ex ante form of the penalty rule. As discussed in text accompanying notes 47-102 supra, however, there may be a number of reasons why parties stipulate excessive damages. Juxtaposed to those models, this approach provides a more complete theory as to why renegotiation is unlikely, thereby enhancing the robustness of the transaction cost theories. 
APPENDIX

\section{Sketch of the Derivation of the Bargaining Subsidy}

Following is a sketch of the bargaining subsidy necessary to induce efficient breach. For notational convenience, the derivations below are in terms of millions. It is in the spirit of Myerson and Satterthwaite ${ }^{163}$ and Spier, ${ }^{164}$ but it involves a more general form of reservation utility functions. Using the equations in the text accompanying notes 130-131 supra, the following identity emerges for bargaining mechanism $(\mathrm{p}, \mathrm{s})$ :

$$
\begin{aligned}
E\left\{v_{\Delta}-v_{\pi} \mid p, s\right\} & \equiv{ }^{1} \int_{0}^{1} \int_{0}\left(v_{\Delta}-v_{\pi}\right) p\left(v_{\Delta}, v_{\pi}\right) d v_{\pi} d v_{\Delta} \\
& ={ }^{1} \int_{0}\left[u_{\Delta}\left(v_{\Delta}\right)+\mu_{\Delta}\left(v_{\Delta}\right)\right] d v_{\Delta}+ \\
& { }_{0}^{1}\left[u_{\pi}\left(v_{\pi}\right)+\mu_{\pi}\left(v_{\pi}\right)\right] d v_{\pi}
\end{aligned}
$$

Next, for any pair of valuations $(a, b)$ in the unit square $[0,1] \times[0,1]$ the incentive compatibility conditions $\left(\mathrm{IC}_{\pi}\right)$ and $\left(\mathrm{IC}_{\Delta}\right)$ and the envelope theorem imply the following conditions, which must hold true "almost everywhere" for any incentive compatible mechanism:

$$
\begin{aligned}
& \mathrm{u}_{\Delta}\left(\mathrm{v}_{\Delta}\right)=\mathrm{u}_{\Delta}(\mathrm{a})+{ }^{v \Delta} \int_{a}^{1} \int_{0} \mathrm{p}\left(\mathrm{t}_{n}, \mathrm{t}_{\Delta}\right) \mathrm{dt}_{\pi} \mathrm{dt}_{\Delta}+\mu_{\Delta} \text { (a) }-\mu_{\Delta}\left(\mathrm{v}_{\Delta}\right) \\
& u_{n}\left(v_{n}\right)=u_{n}(b)+\int_{v \pi} \int_{0} p\left(t_{n}, t_{\Delta}\right) d t_{\Delta} d t_{n}+\mu_{n}(b)-\mu_{n}\left(v_{n}\right)
\end{aligned}
$$

Substituting these expressions into the above identity, we obtain:

$$
\begin{aligned}
u_{\Delta}(a)+u_{\pi}(b)= & { }^{1} \int_{0}^{1} \int_{0}\left(2 v_{\Delta}-2 v_{\pi}-1\right) p\left(v_{\Delta}, v_{\pi}\right) d v_{\pi} d v_{\Delta} \\
& +{ }^{2} \int_{0}^{1} \int_{0} p\left(t_{\pi}, t_{\Delta}\right) d t_{\pi} d t_{\Delta}+{ }^{1} \int_{b} J_{0} p\left(t_{\pi}, t_{\Delta}\right) d t_{\Delta} d t_{\pi} \\
& -\mu_{\Delta} \text { (a) }-\mu_{\pi} \text { (b) }
\end{aligned}
$$

The above equation is the "workhorse" for the derivation of the necessary subsidy. The procedure for calculating it is the following: For each damages measure $D$ and each legal rule [FE, ENE, NNE], first calculate the equilibrium strategies and associated payoffs $\left(\mu_{\pi}\left(v_{\pi}\right)\right.$ and $\left.\mu_{\Delta}\left(v_{\Delta}\right)\right)$ for the "litigation game" $\Gamma$ pictured in Figure 4. Substituting those reservation utilities into the incentive compatibility constraints, along with the "efficient breach" function $\mathrm{p}\left(\mathrm{v}_{\pi}, \mathrm{v}_{\Delta}\right)$ defined in note 133 supra, it is possible to determine which "types" of $\pi$ and $\Delta$ have the lowest payoff under an efficient breach mechanism. Let these types be the pair $(a, b)$ defined above. The individual rationality constraints require that all types of both players must get at least their reservation utilities under this mechanism. Thus, we should make sure that these "lowest types" get at least their reservation utilities $\mu_{\pi}(\mathrm{a})$ and $\mu_{\Delta}$ (b) from the mechanism. This implies that:

$$
\mathrm{u}_{\Delta}(\mathrm{a})+\mathrm{u}_{\pi}(\mathrm{b}) \geq 0
$$

Thus, if the right hand side of the "workhorse" equation above is negative, then an outside subsidy is required so that the "lowest types" find it rational to participate. Hence, the subsidy is simply the negative of the right hand side of the "workhorse" evaluated at the appropriate $(a, b) .{ }^{165}$

163. See Myerson \& Satterthwaite, supra note 17.

164. See Spier, supra note 123.

165. The explicit calculations are given in Talley, supra note 128 . 
HeinOnline -- 46 Stan. L. Rev. 1244 1993-1994 